\title{
Assessment of the Contribution of a Thermodynamic and Mechanical Destabilization of Myosin-Binding Protein C Domain C2 to the Pathomechanism of Hypertrophic Cardiomyopathy-Causing Double Mutation MYBPC3 ${ }^{\triangle 25 b p / D 389 V}$
}

\author{
Frederic V. Schwäbe ${ }^{1}\left(\mathbb{D}\right.$, Emanuel K. Peter $^{1}$, Manuel H. Taft ${ }^{1} \mathbb{D}$ and Dietmar J. Manstein ${ }^{1,2, *(\mathbb{D})}$ \\ 1 Fritz Hartmann Centre for Medical Research, Institute for Biophysical Chemistry, Hannover Medical School, \\ Carl Neuberg Str. 1, D-30625 Hannover, Germany; Schwaebe.Frederic@mh-hannover.de (F.V.S.); \\ Peter.Emanuel@mh-hannover.de (E.K.P.); Taft.Manuel@mh-hannover.de (M.H.T.) \\ 2 Division for Structural Biochemistry, Hannover Medical School, Carl Neuberg Str. 1, \\ D-30625 Hannover, Germany \\ * Correspondence: Manstein.Dietmar@mh-hannover.de
}

Citation: Schwäbe, F.V.; Peter, E.K.; Taft, M.H.; Manstein, D.J. Assessment of the Contribution of a

Thermodynamic and Mechanical Destabilization of Myosin-Binding Protein C Domain C2 to the Pathomechanism of Hypertrophic Cardiomyopathy-Causing Double Mutation MYBPC $3^{\triangle 25 b p / D 389 V}$. Int. J. Mol. Sci. 2021, 22, 11949. https:// doi.org/10.3390/ijms222111949

Academic Editor: Ian A. Nicholls

Received: 11 October 2021

Accepted: 2 November 2021

Published: 4 November 2021

Publisher's Note: MDPI stays neutral with regard to jurisdictional claims in published maps and institutional affiliations.

Copyright: (c) 2021 by the authors. Licensee MDPI, Basel, Switzerland. This article is an open access article distributed under the terms and conditions of the Creative Commons Attribution (CC BY) license (https:/ / creativecommons.org/licenses/by/ $4.0 /)$.

\begin{abstract}
Mutations in the gene encoding cardiac myosin-binding protein-C (MyBPC), a thick filament assembly protein that stabilizes sarcomeric structure and regulates cardiac function, are a common cause for the development of hypertrophic cardiomyopathy. About $10 \%$ of carriers of the $\triangle 25 \mathrm{bp}$ variant of $M Y B P C 3$, which is common in individuals from South Asia, are also carriers of the D389V variant on the same allele. Compared with noncarriers and those with MYBPC $3^{\triangle 25 b p}$ alone, indicators for the development of hypertrophic cardiomyopathy occur with increased frequency in MYBPC $3^{\triangle 25 b p / D 389 V}$ carriers. Residue D389 lies in the IgI-like C2 domain that is part of the N-terminal region of MyBPC. To probe the effects of mutation D389V on structure, thermostability, and proteinprotein interactions, we produced and characterized wild-type and mutant constructs corresponding to the isolated $10 \mathrm{kDa} \mathrm{C} 2$ domain and a $52 \mathrm{kDa}$ N-terminal fragment that includes subdomains $\mathrm{C} 0$ to C2. Our results show marked reductions in the melting temperatures of D389V mutant constructs. Interactions of construct C0-C2 D389V with the cardiac isoforms of myosin-2 and actin remain unchanged. Molecular dynamics simulations reveal changes in the stiffness and conformer dynamics of domain C2 caused by mutation D389V. Our results suggest a pathomechanism for the development of HCM based on the toxic buildup of misfolded protein in young MYBPC $3^{\triangle 25 \mathrm{bp} / \mathrm{D} 389 \mathrm{~V}}$ carriers that is supplanted and enhanced by C-zone haploinsufficiency at older ages.
\end{abstract}

Keywords: hypertrophic cardiomyopathy; heart disorder; MyBPC; enhanced molecular dynamics simulations; allosteric trigger; cardiac contractility; force generation; protein unfolding

\section{Introduction}

Hypertrophic cardiomyopathy (HCM) is the most common genetic cardiac disorder [1-4]. It is mainly characterized by an increased left ventricular wall thickness and myocyte disarray [5]. Clinical effects vary widely, ranging from no symptoms to shortness of breath, chest pain, atrial fibrillation, or sudden cardiac death. This is related to the fact that the disease can be caused by more than 1400 mutations in at least 11 different genes, with MYBPC3 and MYH7 alone responsible for about 70-80\% of cases [2,6,7].

Mutations in sarcomeric genes often perturb the carefully regulated interplay of thick myosin-containing and thin actin-containing filaments, which is essential for cardiac function. During contraction, myosin periodically interacts with actin in $\mathrm{Ca}^{2+}$-dependent manner, with tropomyosin and the troponin complex playing a regulatory role. In addition, cardiac myosin-binding protein C (MyBPC) carries out multiple regulatory functions. Cardiac MyBPC (encoded by the gene MYBPC3) is one of three MyBPC isoforms, alongside its slow (MYBPC1) and fast (MYBPC2) counterparts in skeletal muscle. MyBPC is a modular 
protein of $140 \mathrm{kDa}$ that comprises eight IgI-like domains, three FnIII-like domains, and one unique $\mathrm{M}$ domain (Figure 1A). The $\mathrm{M}$ domain harbors multiple phosphorylation sites that modulate protein-protein interactions and are implicated in cardiac disease (as reviewed by $[8,9])$. MyBPC is anchored to the thick filament via its C-terminal C8-C10 domains [10-12], while its N-terminal domains interact with actin and different myosin subdomains [13-20]. Binding to myosin S2 has been demonstrated to promote myosin's super-relaxed state, limiting the number of heads accessible for contraction [21-23]. Its interaction with cardiac thin filaments is thought to sensitize the sarcomere for $\mathrm{Ca}^{2+}$ by azimuthally displacing tropomyosin [24,25]. Moreover, it can apply a viscous load by tethering the thick and the thin filament, thus acting as a brake to cardiac contraction with precisely defined mechanochemical properties [26-28].

A

F-Actin

Titin
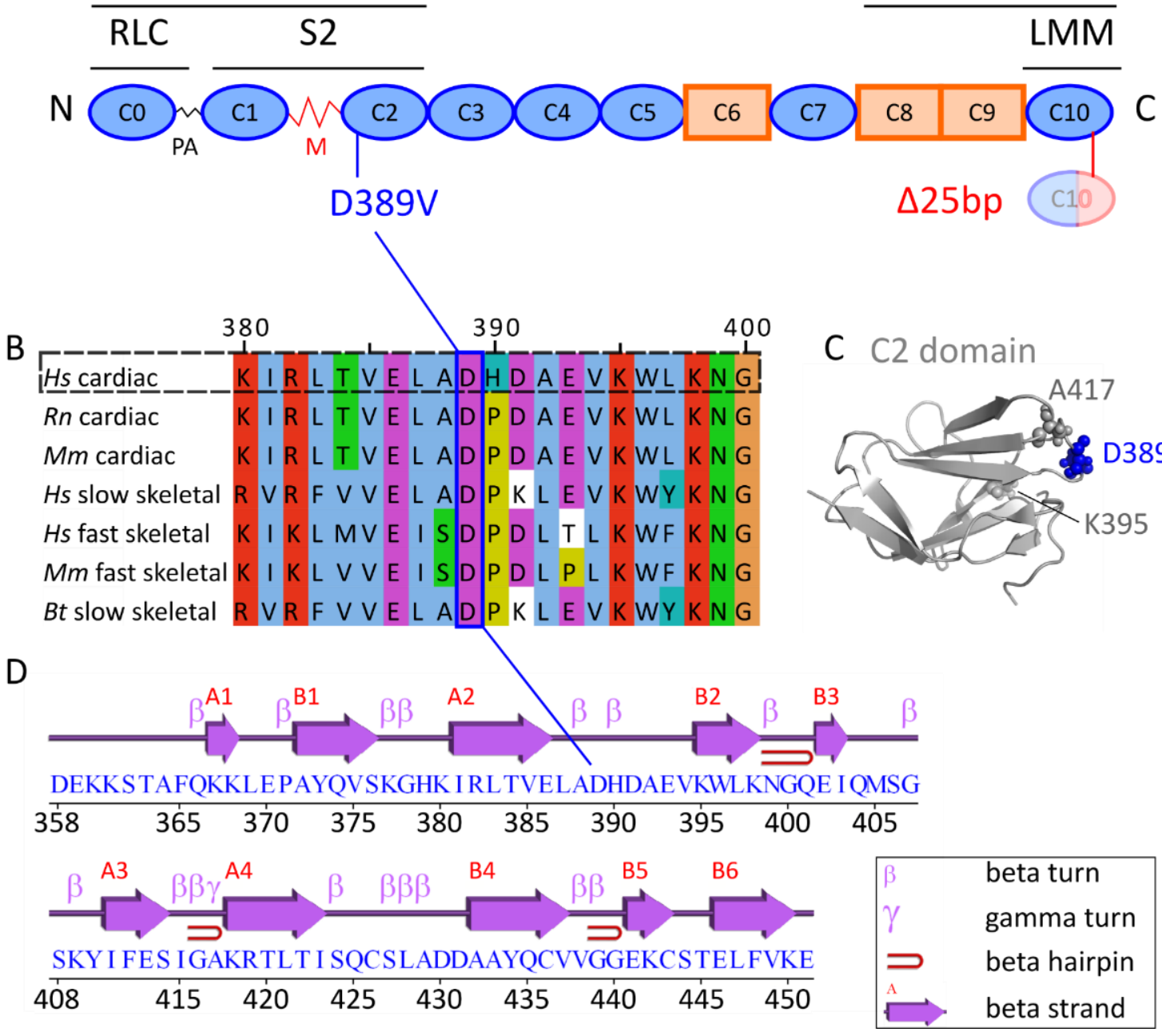

Figure 1. Schematic diagram showing the domain organization of MyBPC and its C2 domain. (A) MyBPC consists of eight IgI-like domains (blue), three FnIII-like domains (orange), and one unique M domain. Binding partners are indicated above the respective subdomains. The positions of the $M Y B P C 3^{\triangle 25 b p / D 389 V}$ mutation are indicated. PA: proline-alanine-rich region. (B) Alignment of MyBPC C2 protein sequences. Residue D389 is highly conserved across different mammalian isoforms. Rn: Rattus norvegicus, Mm: Mus musculus, Hs: Homo sapiens, Bt: Bos taurus. Alignment was created using T-Coffee [29] and Jalview [30]. (C) Cartoon representation of the MyBPC C2 domain (PDB: 5k6p [31]) with relevant residues D389, K395, and A417 displayed as spheres. (D) Domain topology scheme of the C2 domain as generated by EMBL-EBI PDBsum (https://bio.tools/pdbsum_generate; last accessed on 1 November 2021). A1-A4 and B1-B6 represent strands of the $\beta$-sheets $A$ and $B$. 
The majority of pathogenic MYBPC3 mutations result in the production of a truncated protein, inducing HCM through a reduced amount of functional MyBPC (haploinsufficiency) [32-37]. In contrast, single amino acid replacements often destabilize a subdomain or alter protein-protein interactions, promoting development of HCM via alternative pathomechanisms [32,38-42].

The common $M Y B P C 3^{\triangle 25 b p}$ variant with a 25 base pair deletion in intron 32 has been associated with an increased odds ratio of 6.99 for the development of HCM, affecting an estimated 100 million carriers in the South Asian population [43-45]. These studies show that transcripts originating from the affected allele are subject to alternative splicing mechanisms that lead to skipping of exon 33. The resulting protein, which has an altered C10 domain with 62 residues removed and 55 newly added, mislocalizes to the Z-disc. It has been shown that overproduction of the modified protein is sufficient to cause HCM in transgenic mice [46,47]. However, whether a corresponding alternative splicing process in humans also results in the production of significant amounts of the modified protein and its mislocalization remains to be confirmed.

More recently, the D389V mutation in the $\mathrm{C} 2$ domain was discovered in $\sim 10 \%$ of the $M Y B P C 3^{\triangle 25 b p}$ carriers, constituting the monoallelic $M Y B P C 3^{\triangle 25 b p / D 389 V}$ double mutation [48]. Individuals carrying this mutation exhibit increased left ventricular ejection fraction, left ventricular fractional shortening, and cardiomyocyte hypertrophy. These features, which are considered early findings of HCM, are not observed in an MYBPC $3^{\triangle 25 b p}$ control cohort.

While many previous studies utilized C0-C2 or C1-C2 constructs [13-20], little is known about the biochemical properties of the isolated $C 2$ domain. Since MYBPC $3^{\triangle 25 b p}$ alone is not a penetrant factor for the development of HCM and has been characterized before [45-48], our study focuses on the impact of the D389V mutation in the C2 domain of MyBPC. Residue D389 lies in a region of the C2 domain that is highly conserved across mammals (Figure 1B). The IgI-like domain consists of $10 \beta$-strands that form two $\beta$-sheets (Figure 1C,D).

Here, we used a multifaceted approach to elucidate the role of the $\mathrm{C} 2$ domain and determine which of the versatile regulatory mechanisms of MyBPC are perturbed by mutation D389V. Correlation-guided enhanced molecular dynamics sampling (CORE-MD II) was applied to study the conformational space of the C2 domain [49-51] (see Section 4 for more details). The method relies in part on the partitioning of the entire pathway into short trajectories that we refer to as instances. The CORE-MD II sampling within each instance is accelerated by adaptive path-dependent metadynamics simulations. The second part of the enhanced sampling MD approach involves kinetic Monte Carlo (kMC) sampling between the different configurations that are accessed during each instance. The combination of the partition of the total simulation into short nonequilibrium simulations and the kMC sampling facilitates the sampling of rare events of protein dynamics on long timescales without definitions of a priori reaction pathways and additional parameters. Therefore, CORE-MD II provides an acceleration factor of at least 100, as validated by folding simulations of sample peptides [51]. Additionally, we used biochemical approaches to probe the structure, thermostability, and protein-protein interactions of the N-terminal domains of MyBPC.

\section{Results}

\subsection{Enhanced CORE-MD II Simulations of the Wild Type and the D389V C2 Domain}

We performed enhanced correlation-guided CORE-MD II simulations on the C2 wild type (wt) and the D389V domain for 100 ns each [49-51]. In Figure S1, we display relevant conformers that we extracted from the simulations at different points in time. In the visual analysis of the conformations, we observe that the $\mathrm{N}$-terminal triple $\beta$-sheet structure remains relatively stable throughout the simulation in both $\mathrm{C} 2 \mathrm{wt}$ and $\mathrm{D} 389 \mathrm{~V}$, whereas the C-terminal region of both proteins exhibits a stronger flexibility and populates a wider conformation range. 
We continued with the analysis of the region in proximity to position 389 . We determined the associated free energy landscapes as a function of the interatomic distances between D389 C $\gamma(w \mathrm{t}) / \mathrm{V} 389 \mathrm{C} \beta-\mathrm{K} 395 \mathrm{~N} \zeta$ and D389 $\mathrm{C} \gamma(\mathrm{wt}) / \mathrm{V} 389 \mathrm{C} \beta-\mathrm{A} 417 \mathrm{C} \alpha$ averaged over the simulation. In Figure 2, we show the free energy landscapes determined for C2 wt and D389V. In the free energy landscape analysis of the wild type, we find four major minima surrounded by a region that is higher in free energy. States (1-3) reside at a distance D389-A417 of approximately $1.1 \mathrm{~nm}$. State (1) corresponds to the formation of a salt bridge between D389 and K395 (see Figure 2A). States (2-3) represent intermediate states. State (4) is defined by a strong interaction of the D389 backbone with both the amino group of K395 and the backbone carbonyl group of the adjacent residue A417.

A

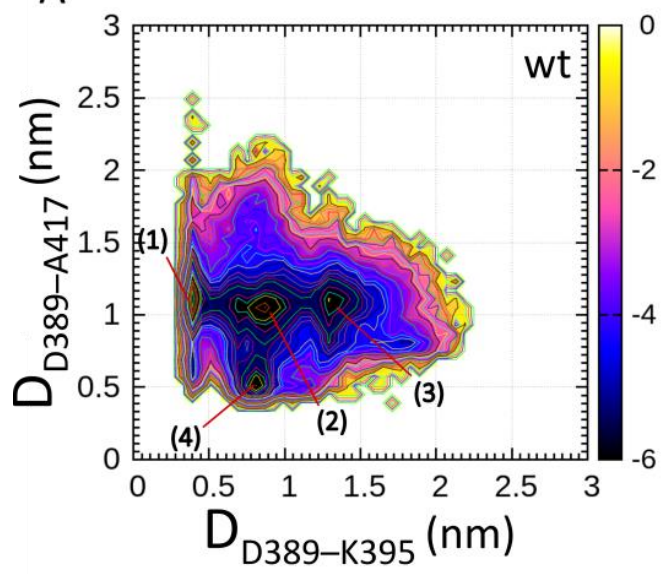

C

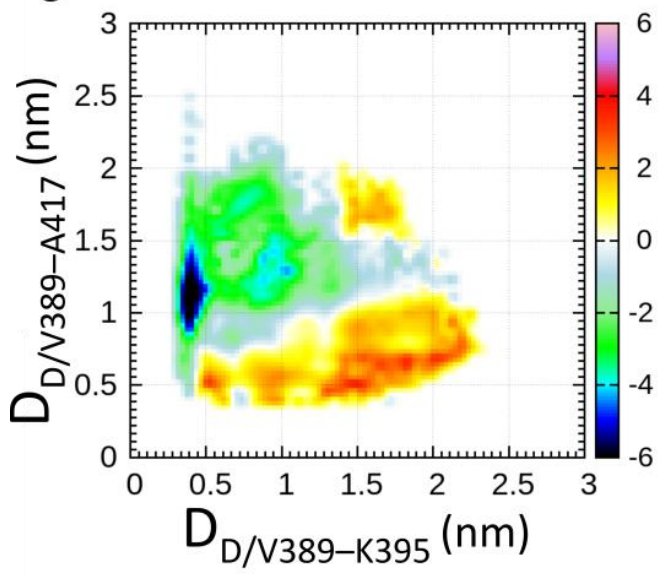

B

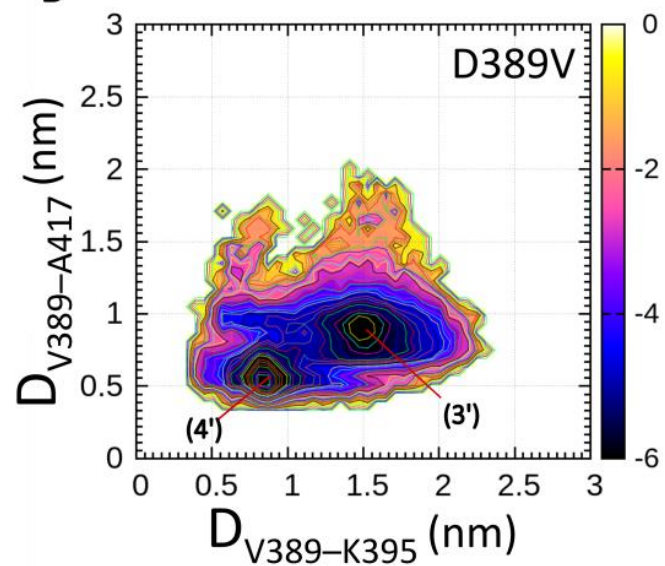

D

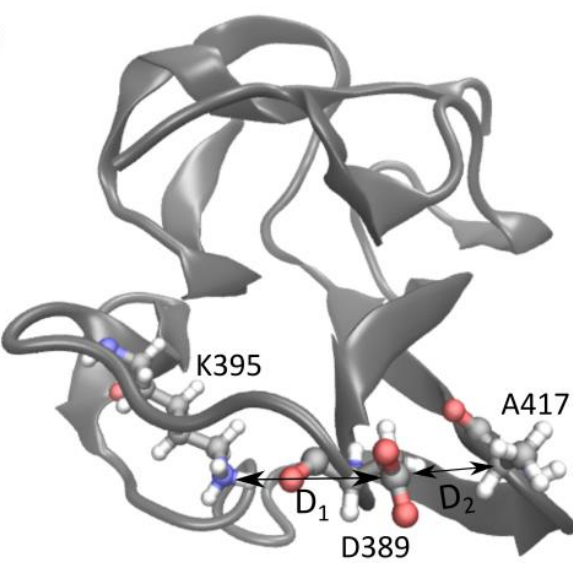

Figure 2. Free energy landscapes of MyBPC C2 wt (A) and D389V (B) domains generated using 100 ns of CORE-MD II simulations. The effect of the D389V mutation on the conformational space in the vicinity of the mutation is explored. We define the interatomic distances between D389V $\mathrm{C} \gamma / \mathrm{V} 389 \mathrm{C} \beta-\mathrm{K} 395 \mathrm{~N} \zeta$ and D389V C $\gamma / \mathrm{V} 389 \mathrm{C} \beta-\mathrm{A} 417 \mathrm{C} \alpha$ as principal coordinates of the FEL. The scale of the color bar is given in units of $\mathrm{k}_{\mathrm{B}} \mathrm{T}$ and represents the free energy $\Delta F$ (see Equation (5), Section 4.3). (1) to (4) indicate conformational states of $C 2 \mathrm{wt}$, and $\left(3^{\prime}\right)$ and $\left(4^{\prime}\right)$ indicate those of $\mathrm{C} 2$ D389V. (C) Free energy differences $\Delta \Delta F$ between C2 wt and C2 D389V (see Equation (6), Section 4.3). Negative values indicate an abundance of wt, and positive values indicate an abundance of D389V states. (D) Sample conformer extracted from State (4) in (A). C2 wt is depicted with the interacting residues D389, K395, and $A 417$. $D_{1}$ represents the $\mathrm{x}$-axis and $\mathrm{D}_{2}$ represents the $\mathrm{y}$-axis of the distances plotted in figures (A) to (C) for all conformations adapted over the course of the simulation.

A sample conformer of State (4) is displayed in Figure 2D. The C2 D389V free energy landscape (Figure 2B) and the difference map between C2 wt and D389V (Figure 2C) reveal 
common features and differences in the population of conformational states. Predictably, State (1) and State (2) are not populated for C2 D389V, as their emergence relies on the stabilizing effect of the salt bridge formed between D389 and K395. State ( $\left.3^{\prime}\right)$ of C2 D389V resembles State (3) of wt but is characterized by the presence of additional hydrophobic contacts. It is the favorable conformation for $\mathrm{C} 2 \mathrm{D} 389 \mathrm{~V}$, as it features a broad continuum of low energy states around its minimum. States (4) of wt and (4') of D389V share similar coordinates in the free energy landscape, which shows that the mutation of the amino acid side chain does not significantly affect backbone interactions of residue 389 .

Free energy landscape analysis reveals that mutation D389V leads to a shift in the conformational equilibrium and the annihilationof States (1-2). We investigated that effect through a kinetic network analysis (see Section 4). Figure 3 shows representative clustered conformations that were selected based on the distances of D389 C $\gamma$ or V389 C $\beta$ to K395 N 2 and $\mathrm{A} 417 \mathrm{C} \alpha$. The analysis of $\mathrm{C} 2 \mathrm{wt}$ shows that all states have a similar occupancy. State (2) mediates the transitions between States (1), (3), and (4), as indicated by their transition probabilities with State (2). The D389V mutation prevents the occupancy of States (1) and (2), leading to a high prevalence of State $\left(3^{\prime}\right)$ and a slight increase in the population of State $\left(4^{\prime}\right)$, compared to State (4) for C2 wt. Hence, the local perturbation by mutation D389V appears to have an allosteric effect that involves the occupancy of the energetic minima together with the associated kinetic network of state transitions, resulting in a reduction in the overall stability of the $\mathrm{C} 2$ domain $[52,53]$.

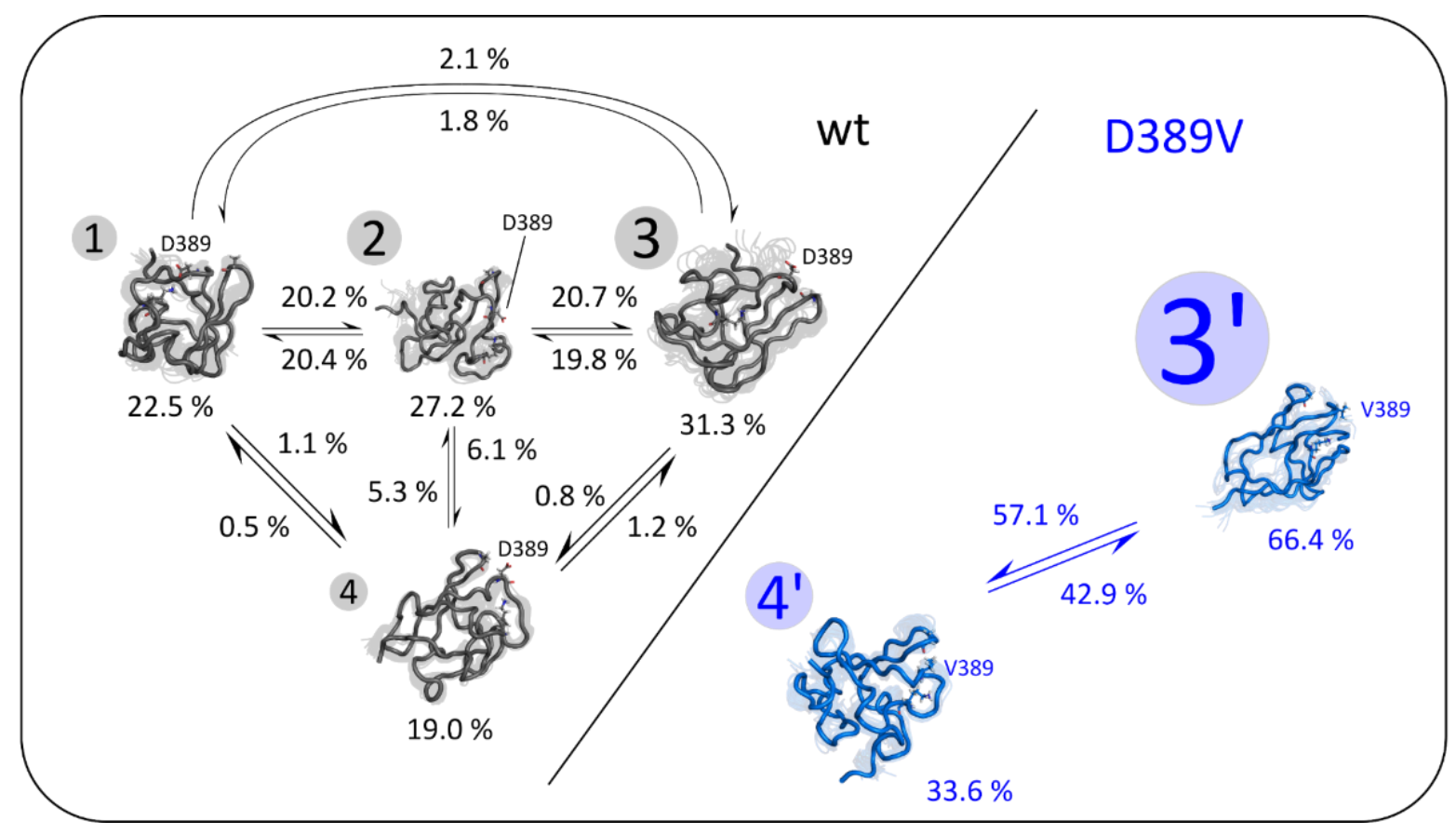

Figure 3. Kinetic network representation derived from the clustered major conformations of C2 wt and D389V. Representative conformations of the States (1) to (4) identified in Figure 2 are shown for C2 wt (black), and $\left(3^{\prime}\right)$ and $\left(4^{\prime}\right)$ are shown for D389V (blue). Backbone C $\alpha$ is shown as a tube representation, and the side chains of residues D389, V389, K395, and A417 are shown as ball-and-stick models with CPK coloring. The opaque underlay displays 40 conformers of each state. The numbers with circular background denote different states. Their size corresponds to the relative occupancy of each state over the course of the simulation, which is shown below the respective conformers. Arrows and percentages reflect probabilities of transition between two states.

To elucidate the effect of $\mathrm{D} 389 \mathrm{~V}$ on the global conformation of the $\mathrm{C} 2$ domain in more detail, we determined time-averaged distance maps for C2 wt and D389V (Figure 4A,B). Here, the main differences between $\mathrm{C} 2 \mathrm{wt}$ and $\mathrm{D} 389 \mathrm{~V}$ manifest themselves in relation to the $\beta$-strand contacts B4-B5-B6 ( $\left.\beta_{4-5-6}\right)$ and B1-B6 ( $\left.\beta_{1-6}\right)$ (see Figure 1D). C2 wt exhibits a tight network of interactions involving residues L421-E451 in $\beta_{4-5-6}$, while the number of corre- 
sponding interactions is substantially reduced in C2 D389V (dotted boxes in Figure 4A,B). In particular, residues L421-D431 are no longer located near residues C436-E441, indicating destabilization or loss of critical $\beta$-strand contacts. The structural consequences of these observations are illustrated in Figure 4C,D for wt and D389V, respectively. A sample conformer of wt protein is shown in grey, and D389V is shown in blue, with both having residues $\mathrm{D} 430-\mathrm{K} 450$ colored in red. The C-terminal region of $\mathrm{C} 2 \mathrm{wt}$ is predicted to populate a larger ensemble of conformer structures compared to the initial NMR ensemble, where stabilizing interactions remain largely intact. For C2 D389V, residues D430-K450 adopt conformations that have a lower propensity for the formation of contacts $\beta_{4-5-6}$. Furthermore, contacts between residues Q401-S406 and residues in the proximity of K380 are weakened, while new contacts are established between residues A392-L397 with the $\mathrm{N}$-terminal region. Additionally, the missing salt-bridge interaction destabilizes the interaction between the N-terminal strand B1 and C-terminal strand B6, as indicated by the dashed boxes in Figure 4A,B. In summary, the effects implied by CORE-MD II simulations make it likely that protein thermodynamic properties are altered. We followed this lead by performing the pertinent biochemical experiments.

A
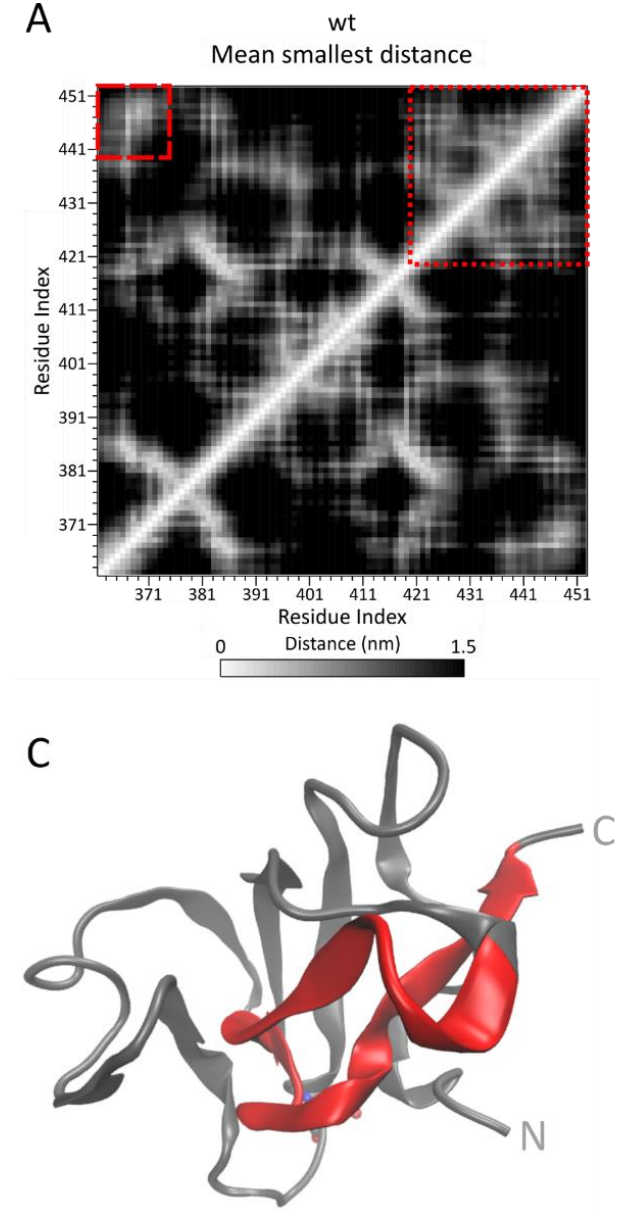

B

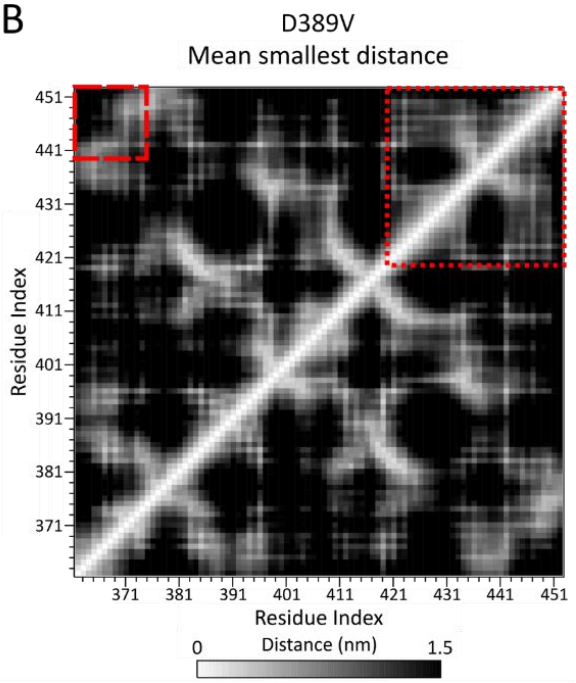

D

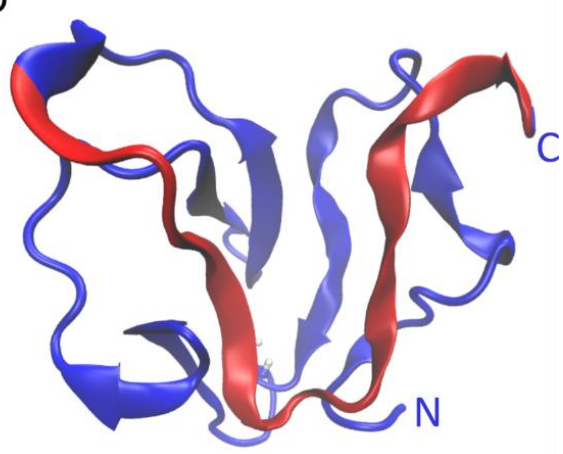

Figure 4. Mean smallest distance matrices for MyBPC C2 wt (A) and D389V (B). The time-averaged minimum distance of each residue to every other residue is plotted in heat maps with white indicating the smallest distance and black indicating the largest distance ranging from 0 to $1.5 \mathrm{~nm}$. This map reveals differences in the global conformational space of C2 wt and D389V. Dotted boxes indicate the $\beta_{4-5-6}$ interstrand contacts within the C-terminus of the domain. Dashed boxes indicate the $\beta_{1-6}$ interstrand contacts of $\mathrm{C} 2 \mathrm{wt}$ that are destabilized in C2 D389V (for topology see Figure 1D). (C,D) Sample structures of C2 wt (grey) and D389V (blue) to illustrate the differences in C-terminal conformation regarding the dotted boxes in (A,B). Residues 430 to 450 are marked in red. 


\subsection{Structural Integrity and Thermodynamic Stability of N-Terminal MyBPC Domains}

Proteins were prepared as described in Section 4, and purity was assessed by densitometric analysis of a Coomassie Brilliant Blue-stained SDS gel (Figure S2). $\beta$-Cardiac myosin $(\beta-\mathrm{CM})$ and $\alpha$-cardiac actin were approximately $95 \%$ and $98 \%$ pure. The MyBPC $\mathrm{C} 2$ and $\mathrm{C} 0-\mathrm{C} 2$ constructs of wt and D389V had a purity of $>99 \%$.

Depending on their character and position in the protein, point mutations may perturb protein structure by different mechanisms, such as impairment of folding pathways or loss of stabilizing side-chain interactions. We performed circular dichroism (CD) experiments to assess the impact of mutation D389V on C2 secondary structure composition. Moreover, we probed C2 domain thermostability using the thermal shift assay (TSA) and differential scanning calorimetry (DSC). The values for the secondary structure composition and melting temperatures of the MyBPC C2 and C0-C2 wt and D389V constructs are summarized in Table 1. CD spectra of the averaged data for each construct and the respective TSA and DSC traces are shown in Figures S3 and S4. CD, TSA, and DSC data indicate that all protein constructs possess a stable fold. CD spectra show that the C2 wt domain consists of $35-40 \%$ $\beta$-sheets and 30-35\% unordered regions with approximately 10\% $\alpha$-helical and $20 \% \beta$-turn content. These data are in good agreement with published NMR structures [31]. Our CD data indicate no major structural perturbations of the N-terminal domains of MyBPC by the $\mathrm{D} 389 \mathrm{~V}$ mutation.

Table 1. Structural and thermodynamic analysis of N-terminal MyBPC domains as determined by CD experiments, TSA and DSC. $\alpha$ : $\alpha$-helix, $\beta$ : $\beta$-sheet, T: turn, $\mathrm{U}$ : unordered, $\Sigma$ : total, $\mathrm{T}_{\mathrm{m}}$ : melting temperature. Data are mean $\pm \mathrm{SEM}$ of at least $n=3$ experiments.

\begin{tabular}{cccccccc}
\hline Construct & $\boldsymbol{\alpha}(\mathbf{\%})$ & $\boldsymbol{\beta}(\mathbf{\%})$ & $\mathbf{T}(\mathbf{\%})$ & $\mathbf{U}(\mathbf{\%})$ & $\boldsymbol{\Sigma}(\boldsymbol{\%})$ & $\mathbf{T}_{\mathbf{m}}(\mathbf{T S A}) /{ }^{\circ} \mathbf{C}$ & $\mathbf{T}_{\mathbf{m}}(\mathbf{D S C}) /{ }^{\circ} \mathbf{C}$ \\
\hline C2 wt & 7 & 37 & 22 & 34 & 100 & $59.3 \pm 0.1$ & $56.5 \pm 0.3$ \\
C2 D389V & 7 & 36 & 22 & 35 & 100 & $52.1 \pm 0.3$ & $52.3 \pm 0.2$ \\
C0-C2 wt & 7 & 36 & 24 & 32 & 99 & $51.8 \pm 0.5$ & $50.2 \pm 0.1$ \\
C0-C2 D389V & 8 & 40 & 22 & 30 & 100 & $48.9 \pm 0.6$ & $47.6 \pm 0.3$ \\
\hline
\end{tabular}

Representative melting curves of thermal denaturation experiments are shown in Figure S4. The determined melting temperature $\left(\mathrm{T}_{\mathrm{m}}\right)$ values for the $\mathrm{C} 2 \mathrm{wt}$ domain (59.3 $\pm 0.1{ }^{\circ} \mathrm{C}$ in TSA and $56.5 \pm 0.3{ }^{\circ} \mathrm{C}$ in DSC) are similar to those determined for the MyBPC C 3 and C4 domains that exhibit the same IgI-like fold as the C2 domain $[54,55]$. The reduction in the $\mathrm{T}_{\mathrm{m}}$ for the mutant $\mathrm{C} 0-\mathrm{C} 2$ construct shows that perturbations introduced in $\mathrm{C} 2$ can affect the thermal stability of neighboring $\mathrm{N}$-terminal domains.

\subsection{Interaction of N-Terminal Domains of MyBPC with Key Sarcomeric Proteins}

In order to evaluate the binding affinity of MyBPC constructs $\mathrm{C} 2$ and $\mathrm{C} 0-\mathrm{C} 2$ to Factin and synthetic thick filaments of $\beta-\mathrm{CM}$, we performed high-speed cosedimentation assays. The effect of the interaction of MyBPC with the cardiac thin filament has been studied in detail, leading to the hypothesis that it modulates the actomyosin cross-bridge cycle $[13,15-17]$. In particular, the N-terminal MyBPC C0 domain was shown to bind the regulatory light chain of $\beta-\mathrm{CM}[56]$, and constructs comprising domains $\mathrm{C} 0$ to $\mathrm{C} 2$ were shown to interact with the $\mathrm{S} 2$ region of $\beta-\mathrm{CM}[18,19,57]$. The degree to which C2 D389V alters the interactions between the $\mathrm{N}$-terminus of MyBPC and cardiac thin filaments or $\beta-\mathrm{CM}$ may thus provide a direct indication of the extent of cardiac dysregulation.

High-speed cosedimentation assays probing the affinity of MyBPC C2 to actin or $\beta-\mathrm{CM}$ show very weak interaction (Figure S5). Cosedimentation of $30 \mu \mathrm{M} \mathrm{C} 2 \mathrm{wt}$ and $40 \mu \mathrm{M}$ F-actin or $30 \mu \mathrm{M} \mathrm{C} 2 \mathrm{wt}$ and $2.5 \mu \mathrm{M} \beta-\mathrm{CM}$ resulted in $<2 \%$ of $\mathrm{C} 2$ in the pellet fraction. Based on these results, a $K_{d}$ in the range of several $100 \mu \mathrm{M}$ can be estimated. This very weak binding is consistent with a $\mathrm{K}_{\mathrm{d}}$ of $1.1 \mathrm{mM}$ determined for the interaction of $\mathrm{C} 2$ with domain $\mathrm{S} 2$ of myosin [31]. 
To determine whether the $\mathrm{D} 389 \mathrm{~V}$ mutation affects the binding of other $\mathrm{N}$-terminal domains to $\beta-\mathrm{CM}$ and actin, we performed cosedimentation assays with MyBPC C0-C2 (Figure 5). The $\mathrm{K}_{\mathrm{d}}$ value determined for the interaction of $\mathrm{C} 0-\mathrm{C} 2$ with F-actin of $3.2 \pm 0.9 \mu \mathrm{M}$ is unchanged by the D389V mutation $(2.8 \pm 0.6 \mu \mathrm{M})$. The $\mathrm{K}_{\mathrm{d}}$ value of the interaction of $\beta-\mathrm{CM}$ with $\mathrm{C} 0-\mathrm{C} 2 \mathrm{wt}$ has been calculated to be $12.7 \pm 4.7 \mu \mathrm{M}$, whereas $\mathrm{C} 0-\mathrm{C} 2 \mathrm{D} 389 \mathrm{~V}$ has an affinity of $14.8 \pm 7.7 \mu \mathrm{M}$. The values are consistent with prior studies $[16,18,58,59]$ and indicate no effect of $\mathrm{D} 389 \mathrm{~V}$ on the interaction of the N-terminal region of MyBPC with $\mathrm{F}$-actin and $\beta-\mathrm{CM}$. Since the binding of $\mathrm{C} 0-\mathrm{C} 2$ to $\beta-\mathrm{CM}$ and F-actin is at least two orders of magnitude stronger, it is unlikely that the interactions of the $\mathrm{C} 2$ domain alone are of physiological importance. In fact, several models based on the results obtained with the $\mathrm{C} 0-\mathrm{C} 2$ construct suggest that the $\mathrm{C} 2$ domain does not make direct contact with F-actin [17]. Furthermore, it was shown that a C2-C5 construct does not incorporate into the sarcomere [18].

A

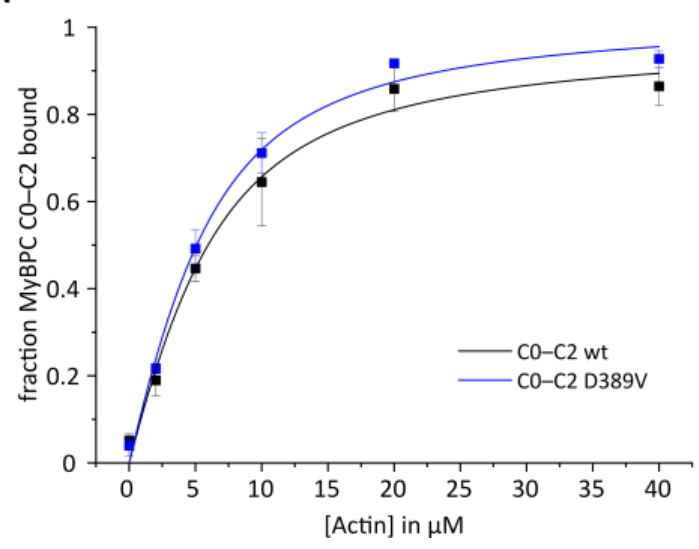

B

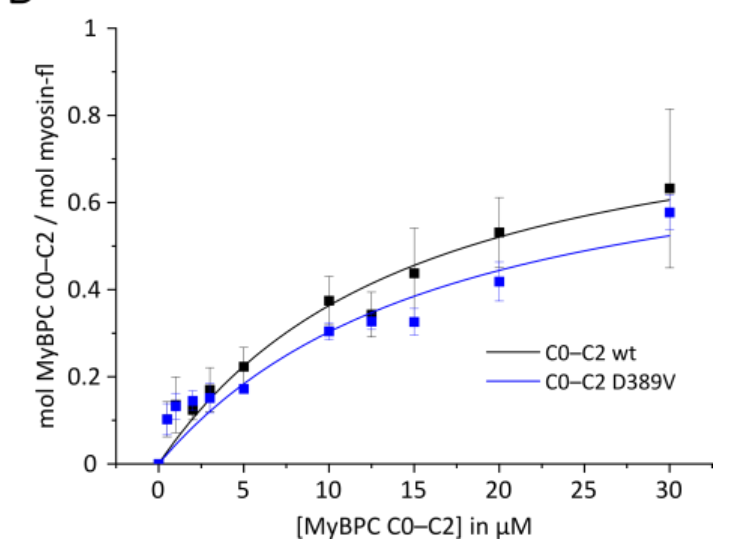

Figure 5. High-speed cosedimentation experiments of MyBPC C0-C2 with F-actin and $\beta$-cardiac myosin. (A) Actin $(0-40 \mu \mathrm{M})$ and MyBPC C0-C2 $(5 \mu \mathrm{M})$ were cosedimented and the fraction of C0-C2 in the pellet was determined. A quadratic fit yields the dissociation constants $\mathrm{K}_{\mathrm{d}}$ for wt of $3.2 \pm 0.9 \mu \mathrm{M}$ and D389V of $2.8 \pm 0.6 \mu \mathrm{M}$. (B) MyBPC C0-C2 $(0-30 \mu \mathrm{M})$ was cosedimented with $2.5 \mu \mathrm{M}$ of $\beta$-cardiac myosin. The amount of $\mathrm{C} 0-\mathrm{C} 2$ bound to synthetic thick filaments was determined using a protein standard range of $\mathrm{C} 0-\mathrm{C} 2$. A quadratic fit yields $\mathrm{K}_{\mathrm{d}}$ values for wt of $12.7 \pm 4.7 \mu \mathrm{M}$ and $\mathrm{D} 389 \mathrm{~V}$ of $14.8 \pm 7.7 \mu \mathrm{M}$. Data points indicate mean $\pm \mathrm{SD}$ from at least $n=3$ experiments.

\subsection{Simulation of C2 Domain Unfolding Dynamics}

Apart from affecting the equilibrium between myosin disordered relaxed and superrelaxed states [19,60-62], MyBPC regulates contractility by acting as a mechanical tether. Electron tomography of cryopreserved muscle specimens shows that MyBPC is not only bound to the thick filament, but also extends out and connects to the thin filaments [63]. The C-terminal region of MyBPC is anchored to thick filaments via domains C8-C10. Additional binding of the $\mathrm{N}$-terminal region of MyBPC to the thin filament establishes a mechanical tether that exerts a viscous load during the cross-bridge cycle [26-28,55]. Using laser-trap assays, the lifetimes of interaction between MyBPC and thin filaments were determined to range from 20 to $300 \mathrm{~ms}$ [28], outlasting actomyosin cross-bridge interactions $(<200 \mu \mathrm{s})$ by at least two orders of magnitude $[55,64]$. Mutations that disrupt the mechanical tether function of MyBPC by reducing the folding stability of individual domains may thereby lead to altered sarcomere activity and thus contribute to HCM pathogenesis.

So far, it remains to be determined to what extent the N-terminal domains of MyBPC are contributing to the interaction with F-actin. While neutron scattering data suggest that domains $\mathrm{C} 0$ and $\mathrm{C} 1$ bind directly to F-actin [17], high-speed cosedimentation and yeast twohybrid assays have shown that domains $\mathrm{C} 1$ and $\mathrm{M}$ are essential for the interaction $[16,65]$. As C8 is the closest domain attached to the thick filament, the intervening linker domains $\mathrm{C} 2-\mathrm{C} 7$ are predestined to unfold when force is applied during active sarcomere contraction. Using an atomic force microscopy-based approach, this model has been applied to HCM 
mutations R495W and R502Q in the C3 domain of MyBPC, which shares a similar IgI-like fold with domain $\mathrm{C} 2$. The unfolding force and the dynamics of unfolding and refolding were examined [55]. Since the C2 domain does not serve as an attachment site on thin filaments, it seems plausible that its function is to act as a brake exerting a set counterforce to cardiac contraction.

To model the mechanical strain to which the C2 domain is subjected, we applied steered molecular dynamics (SMD) simulations [66-68] by pulling on the $\mathrm{C} \alpha$ atom of P452 with constant force while S362C $\alpha$ remained in place (Figure 6). Example traces of force-time curves are shown in Figure 6A. The maximum counterforce occurs at about $1100 \mathrm{ps}$ for C2 D389V and at $2000 \mathrm{ps}$ for C2 wt. This peak corresponds to the loss of the $\beta_{1-6}$ interstrand contacts, as shown in exemplary structures at time points 0,1400 , and $2400 \mathrm{ps}$ in Figure 6B. While the contact $\beta_{1-6}$ is intact at $\mathrm{t}=0$ in both proteins, it is already broken at $\mathrm{t}=1400 \mathrm{ps}$ in C2 D389V. The disruption of this structure in C2 wt happens later, after its major peak, as visualized at $t=2400 \mathrm{ps}$. The destabilizing effect of the D389V mutation on the $\beta_{1-6}$ contacts has already been established by the CORE-MD II simulation (Figure 4). Plots showing the residue matrices facilitate a comparison of the results obtained with both simulation methods and clarify their consistency (Figures S6 and 4).

The averaged force-time curves of 10 individual unfolding simulations are shown in Figure 6C. C2 D389V tends to unfold earlier with a sharper force peak and a higher maximum force. The same force is required to unfold $\mathrm{C} 2 \mathrm{wt}$, but over a longer period of time. This suggests that this part of the C2 D389V structure is more rigid, whereas the $\mathrm{C} 2 \mathrm{wt}$ domain compensates for the applied force by forming various stabilizing contacts during the unfolding process. There were no noticeable differences in the force-time curve for the remaining protein unfolding pathway. Evaluating the time point of the first unfolding peak for each of the 10 experiments reveals that the $\mathrm{C} 2 \mathrm{wt}$ unfolding peak occurs after $1751 \pm 714 \mathrm{ps}$ and 2-fold faster for C2 D389V at $986 \pm 384$ ps (Figure 6D). Applying this unfolding mechanism to the MyBPC viscous load model on sarcomeric contraction implicates a different contraction-over-time pattern for carriers of the D389V mutation, as the C2 D389V domain exhibits different mechanical spring properties than C2 wt. Disruption of the finely tuned cardiac contractile cycle provides a molecular mechanism for the development of HCM. These results provide the basis for further clarification of the pathomechanism of double mutation $M Y B P C 3^{\triangle 25 b p / D 389 V}$. 
A

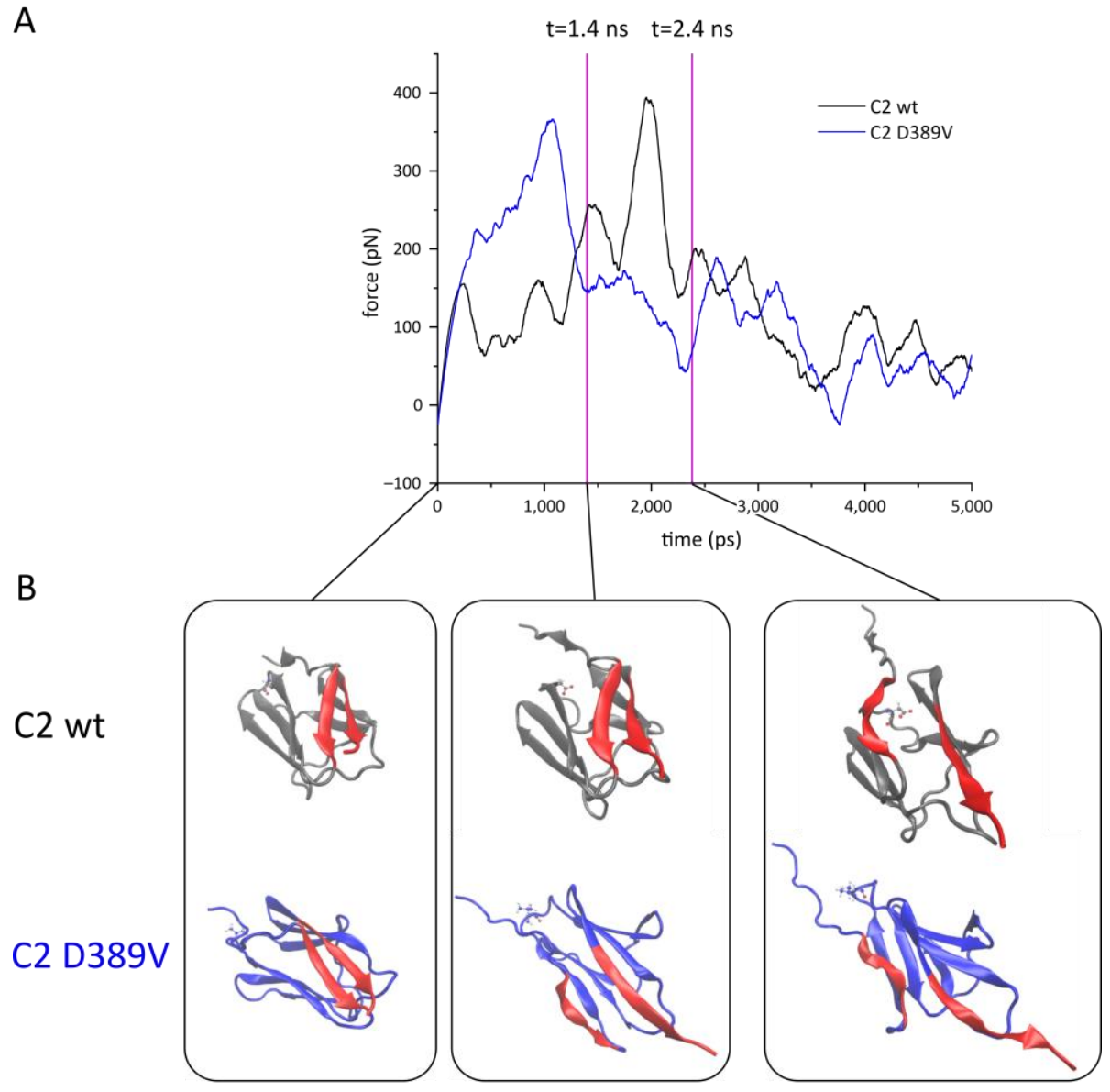

C

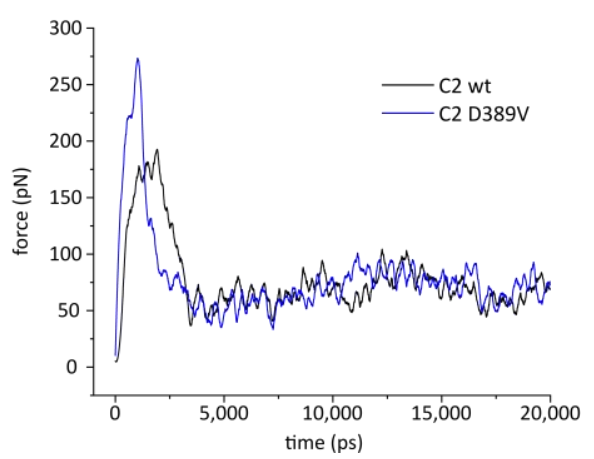

D

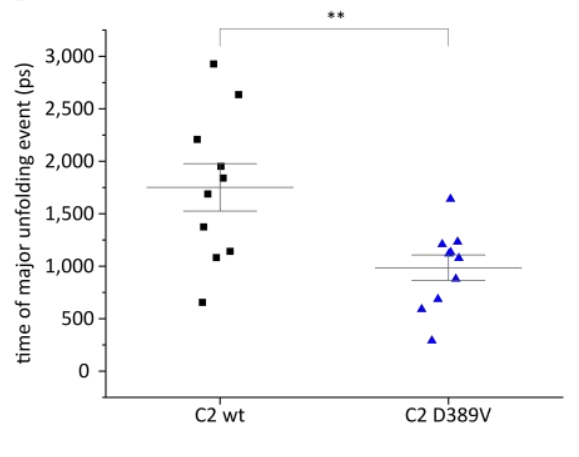

Figure 6. Constant velocity steered molecular dynamics (cvSMD) simulation of MyBPC C2 domain unfolding. The SMD atom P452C $\alpha$ was pulled at a velocity of $0.01 \AA / \mathrm{ps}$ and the spring constant was set to $7 \mathrm{kcal} / \mathrm{mol} / \AA$. (A) Sample traces for an unfolding simulation of each wt and D389V MyBPC C2 domain. The force acting on the SMD atom is plotted against the time of the simulation. Data were smoothened using Savitzky-Golay filter to compensate for the noise created by the spring acting on the fixed atom. (B) Sample structures of time points 0, 1400, and 2400 ps in the unfolding experiments displayed in (A). C2 wt and C2 D389V are shown in grey and blue, respectively, with residue 389 as a CPK model. Residues A372-K377 and T445-P452 of the parallel $\beta_{1-6}$ strands are marked in red. (C) Average of $n=10$ independent unfolding simulations of each wt and D389V MyBPC C2 domain. The force acting on the SMD atom is plotted against the time of the simulation. Data were smoothened using Savitzky-Golay filter to compensate for the noise created by the spring acting on the fixed atom. (D) The time point of the major unfolding event is plotted for each individual unfolding experiment. The major unfolding event is defined as the global maximum of the force-time curve. The peak of unfolding occurred on average after $1751 \pm 714$ ps for wt and $986 \pm 384$ ps for D389V. ${ }^{* *} p<0.01$. 


\section{Discussion}

Mutations in the MYBPC3 gene are among the most common causes for the development of HCM. In this study, we demonstrate that the D389V mutation strongly perturbs the conformational space of the $\mathrm{C} 2$ domain, while leaving the tertiary structure intact. Residue D389 of MyBPC is conserved across many species and isoforms, which appears to be related to its role in the formation of a salt bridge that stabilizes the loop structure in which it resides (Figure 1). Four energetic minima were identified by the use of CORE-MD II simulations, involving the interaction of D389 with K395 and A417 (Figures 2 and 3). Mutation D389V abolishes the electrostatic attraction towards K395, required for the formation and stabilization of States (1) and (2). Consequently, the energy landscape of C2 is distorted and State $\left(3^{\prime}\right)$ becomes the predominant state in C2 D389V. This allosteric trigger event propagates throughout the whole domain and destabilizes the $\beta_{4-5-6}$ and $\beta_{1-6}$ interstrand contacts (Figure 4).

The replacement of single amino acids in MyBPC can in some instances disrupt the tertiary structure of the affected domain, as shown for the A31P mutation in the C0 domain [41]. Our CD data suggest that the D389V mutation does not cause a major structural change in the domain structure of the constructs $\mathrm{C} 2$ and $\mathrm{C} 0-\mathrm{C} 2$ (Table 1 and Figure S3). However, the thermostability of the $\mathrm{C} 2$ and $\mathrm{C} 0-\mathrm{C} 2$ domain constructs is decreased by D389V, as demonstrated by TSA and DSC (Table 1), which indicates a different conformational space occupied by these constructs compared to wt constructs. This is in line with the results that were obtained by CORE-MD II simulations.

To fulfill its regulatory roles, MyBPC depends on the interaction of its $\mathrm{N}$-terminal domains with the key sarcomeric proteins actin and $\beta$-CM $[13,15-19,57]$. Our high-speed cosedimentation data on the isolated $\mathrm{C} 2$ domain in interaction with $\beta$-CM and actin suggest very weak binding (Figure S5), which is consistent with a $\mathrm{K}_{\mathrm{d}}$ value of $1.1 \mathrm{mM}$ previously determined for the interaction of $\mathrm{C} 2$ with the region containing R870 within subfragment-2 of $\beta-\mathrm{CM}$ [31]. The affinities determined for the interaction of $\mathrm{C} 0-\mathrm{C} 2$ with $\beta-\mathrm{CM}$ and actin are at least two orders of magnitude greater, which implies that potential interactions of $\mathrm{C} 2$ make a minor contribution compared to those of the other $\mathrm{N}$-terminal domains. The values are unchanged by the D389V mutation and consistent with those determined in previous studies $[16,18,58,59]$, thus excluding altered affinities as a pathomechanism.

More recently, the paradigm of MyBPC acting as a mechanical tether has come into focus [69]. Studies exposing MyBPC to mechanical strain by the use of atomic force microscopy revealed a structural hierarchy of domain unfolding that is highly conserved across species [26,27]. Our data suggest that $C 2$ is a linker domain that contributes a resisting force during cardiac contraction. A similar mechanism has been proposed for the neighboring $\mathrm{C} 3$ domain that harbors several HCM mutations [55]. SMD simulations were used to explore potential differences in the unfolding pathways of C2 wt and D389V by moving the $\mathrm{C}$-terminus and fixing the $\mathrm{N}$-terminus (Figure 6 and Figure $\mathrm{S6}$ ). Compared to $\mathrm{C} 2 \mathrm{wt}, \beta_{1-}{ }_{6}$ contacts are disrupted twice as fast and with a sharper peak in C2 D389V. In addition, using an enhanced MD simulation method, we found that the weakening of $\beta_{1-6}$ interactions is a direct consequence of mutation D389V (Figure 4).

There are several possibilities for how these data relate to the hyperdynamic findings observed in echocardiograms of $M Y B P C 3^{\triangle 25 b p / D 389 V}$ carriers [48]. The mechanical destabilization of the $\mathrm{C} 2$ domain by the $\mathrm{D} 389 \mathrm{~V}$ mutation results in a reduced capability of MyBPC to apply a resisting force. Moreover, a differential expression of wt and mutant allele across cardiomyocytes, as demonstrated for HCM mutations in MYH7 [70-72], can promote an imbalance in contractility of the myocardium.

MyBPC can only exert its tethering function if it is correctly incorporated into the Czone of the sarcomere. Overproduction of MyBPC ${ }^{\mathrm{C} 10 m u t}$ in rodents has been shown to lead to mislocalization of the protein in Z-discs, contractile dysfunction, and an HCM-like phenotype [47]. The pathogenic effects associated with $M Y B P C 3^{\triangle 25 b p}$ increase with age. Young and middle-aged individuals carrying the deletion are mostly asymptomatic or show only mild hypertrophy, while $90 \%$ of the $M Y B P C 3^{\triangle 25 b p}$ carriers that are older than 60 become 
symptomatic [45]. In contrast, $M Y B P C 3^{\triangle 25 b p / D 389 V}$ carriers exhibit hyperdynamic systolic function with high penetrance already at a young age. These comprise an increased left ventricular ejection fraction, abnormal calcium transients, and cardiomyocyte hypertrophy, features not inherent to $M Y B P C 3^{\Delta 25 b p}$ carriers [48]. Unless the mutation $M Y B P C 3^{\triangle 25 b p / D 389 V}$ leads to the incorporation of mutant protein into the contractile zone of sarcomeres, there is no plausible molecular mechanism to explain the differences between $M Y B P C 3^{\triangle 25 b p}$ and $M Y B P C 3^{\triangle 25 b p / D 389 V}$ carriers. Many of the HCM mutations that are associated with $M Y B P C 3$ are frameshift mutations and result in the formation of truncated proteins. The 25 base pair deletion in intron 32 of $M Y B P C 3^{\triangle 25 b p}$ and $M Y B P C 3^{\triangle 25 b p / D 389 V}$ has been shown to produce mRNA splice variants that lack exon 33. The probability of this event has been suggested to depend on additional risk factors, such as metabolic syndrome or environmental factors [73]. Moreover, alternative splicing has been shown to be a stochastic process, resulting in a range of differently processed mRNA transcripts [74,75]. In fact, this has already been demonstrated for the cardiomyopathy-related gene $L M N A$ [76] and MYBPC3 [77]. New splice isoforms were found in patients with the MYBPC3 c.1898-1G>A splice site alteration, although the canonical mRNA sequence was still the predominant one. Truncated proteins produced as a result of frameshift mutations can potentially exert a poison polypeptide effect. However, because they cannot be productively integrated into sarcomeric structures, they are usually efficiently degraded by the ubiquitin-proteasome system in cardiomyocytes, resulting in a haploinsufficiency phenotype [32-37]. In contrast, single amino acid exchanges in MyBPC reduce the folding stability of affected structural domains without impeding their integration into the contractile zone of sarcomeres. Their increased propensity to irreversibly unfold under the mechanical stress of the contracting sarcomere suggests a poison polypeptide effect as the dominant pathomechanism for MYBPC $^{\mathrm{D} 389 \mathrm{~V}}$ in young and middle-aged mutation carriers [55,78-80].

Differences in the progression of HCM between MYBPC $3^{\Delta 25 b p}$ and $M Y B P C 3^{\triangle 25 b / D 389 V}$ carriers and age-dependent changes in splicing patterns [81-85] suggest a shift in the dominant pathomechanism for elderly $M Y B P C 3^{\triangle 25 b p / D 389 V}$ carriers. The consequences of mutations $M Y B P C 3^{\triangle 25 b p}$ and $M Y B P C 3^{\triangle 25 b p / D 389 V}$ for individuals with a single mutant allele with respect to disease mechanism and the clinical phenotype are schematically depicted in Figure 7. Young carriers exhibit no symptoms or mild conditions because they predominantly produce the wt protein originating from the correctly spliced mRNA. With increasing age, the amount of mutant transcript with skipped exon 33 increases, leading to the production of MyBPC ${ }^{\mathrm{C} 10 m u t}$, which triggers HCM by C-zone haploinsufficiency [47]. Roughly $90 \%$ of $M Y B P C 3^{\triangle 25 b p}$ carriers above the age of 60 are symptomatic for HCM [45].

Young and middle-aged $M Y B P C 3^{\triangle 25 b p / D 389 V}$ carriers produce the protein with a D389V mutation in the $\mathrm{C} 2$ domain and an intact $\mathrm{C} 10$ domain. The protein localizes correctly in the C-zone, where its function is impaired due to its reduced folding stability and sensitivity to mechanical stress. The resulting toxic buildup of misfolded protein impairs sarcomere function. Such a mechanism is compatible with clinical hyperdynamic findings associated with HCM that are observed in $M Y B P C 3^{\triangle 25 b / D 389 V}$ carriers [48]. With increasing age, as for the $M Y B P C 3^{\triangle 25 b p}$ carriers, changes in alternative splicing result in a gradual shift in the production of splice isoforms that encode truncated gene products, which are in part degraded by the ubiquitin-proteasome system or mislocalize to the Z-disc. The main contributing factors to the pathomechanism in older MYBPC $3^{\triangle 25 b p}$ and $M Y B P C 3^{\triangle 25 b p / D 389 V}$ carriers appear therefore to be identical, namely impaired sarcomere function due to C-zone haploinsufficiency with contributions from the mislocalization of truncated protein to the Z-disc. 


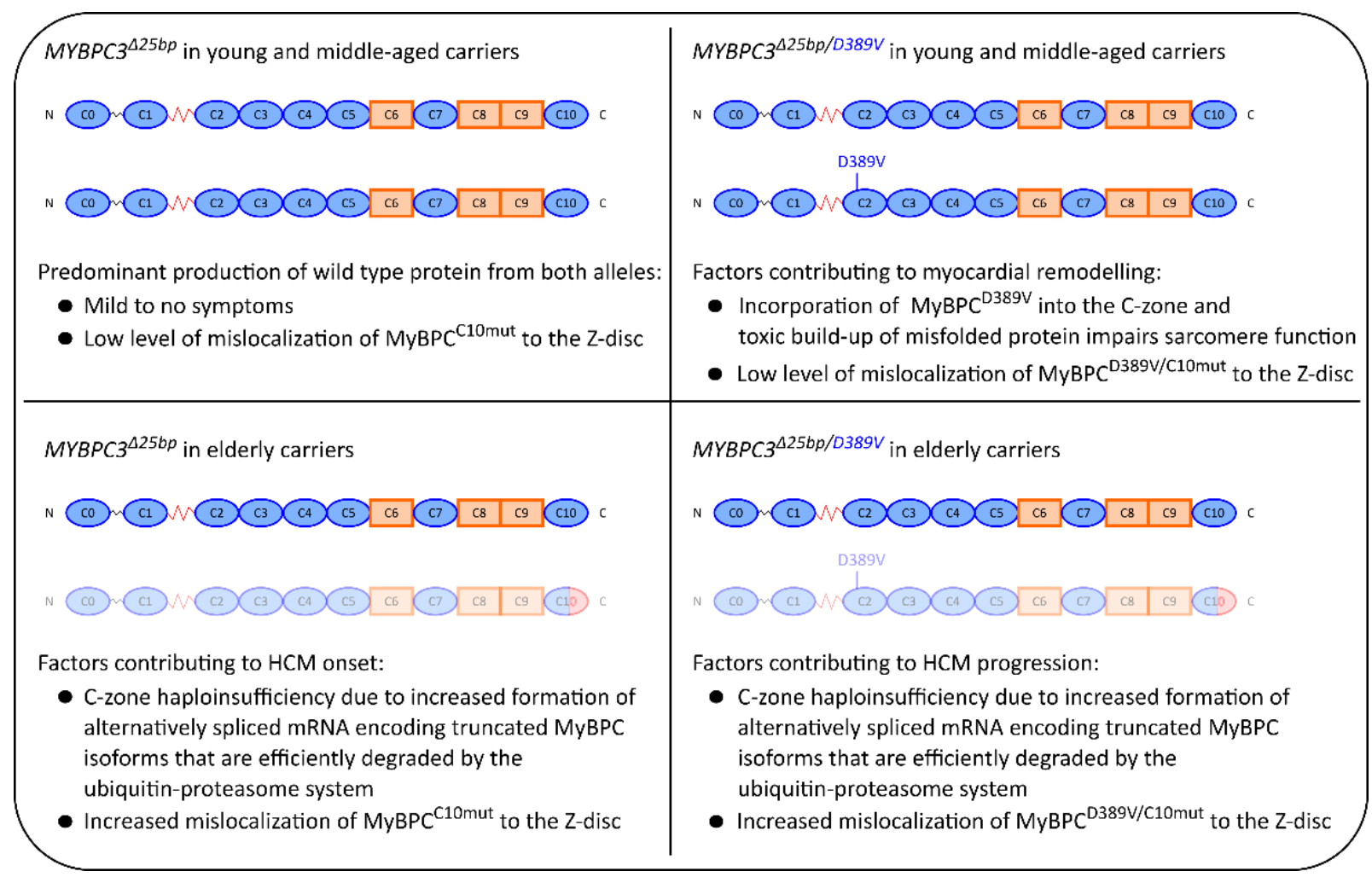

Figure 7. Proposed disease mechanisms as a result of age-related alternative splicing. All carriers in this model are heterozygous for one of the variants and produce wt protein from at least one allele at all times. Young and middleaged $M Y B P C 3^{\triangle 25 b p}$ carriers predominantly produce wt mRNA from both alleles, resulting in mild or absent symptoms. Incorporation of MyBPC ${ }^{\mathrm{D} 389 \mathrm{~V}}$ into the contractile zone of sarcomeres in young and middle-aged $M Y B P C 3^{\triangle 25 b p / D 389 V}$ carriers leads to myocardial remodeling mediated by a poison polypeptide mechanism. As patients age, the alternatively spliced transcript on the allele carrying the intron deletion predominates in both $M Y B P C 3^{\triangle 25 b p}$ and $M Y B P C 3^{\triangle 25 b p / D 389 V}$ carriers. We assume that the truncated forms of the protein are efficiently eliminated by the ubiquitin-proteasome system in cardiomyocytes with smaller fractions of MyBPC ${ }^{\mathrm{C} 10 \mathrm{mut}}$ and MyBPC ${ }^{\mathrm{D} 389 \mathrm{~V} / \mathrm{C} 10 \mathrm{mut}}$ mislocalizing to the Z-disc. As a result, C-zone haploinsufficiency is predicted to become the dominant disease mechanism in elderly $M Y B P C 3^{\triangle 25 b p}$ and $M Y B P C 3^{\triangle 25 b p / D 389 V}$ carriers.

The genotype-phenotype correlations of MyBPC are very diverse due to the multiplicity of genes and environmental factors influencing the clinical outcome. For example, the occurrence of an $M Y H 7$ mutation in $M Y B P C 3^{\triangle 25 b p}$ carriers frequently leads to sudden cardiac death [43]. Extensive genetic screening approaches can discover additional risk factors for genetic variants with an incomplete penetrance for the development of HCM, as has been demonstrated for the $M Y B P C 3^{\triangle 25 b p / D 389 V}$ variant [48]. The pathomechanism largely depends on the ratio of wt to alternatively spliced mRNA transcript originating from the $M Y B P C 3^{\triangle 25 b p}$ allele. This question can be addressed by real-time quantitative PCR (qPCR) on tissue biopsies of $M Y B P C 3^{\triangle 25 b p}$ and $M Y B P C 3^{\triangle 25 b p / D 389 V}$ carriers using mRNA transcript-specific primers. On the protein level, mass spectrometry can provide information on whether and how much MyBPC ${ }^{\mathrm{C} 10 m u t}$ or $\mathrm{MyBPC}^{\mathrm{D} 389 \mathrm{~V} / \mathrm{C} 10 \mathrm{mut}}$ protein is produced in the patients. Understanding the molecular details in the pathogenesis of this life-threatening disease will improve clinical outcome predictions and aid in the development of appropriate treatment regimens.

\section{Materials and Methods}

\subsection{Homology Modeling of the C2 Domain}

Homology models of human MyBPC C2 domain were created from an NMR structure of the $\mathrm{M}$ and $\mathrm{C} 2$ domain (PDB accession code 5k6p [86]) using the software MOD- 
ELLER [87]. Residues 362-452 of human MyBPC (UniProt Q14896) were aligned to the template using the align2d command. The resulting alignment file served as an input for the AutoModel class, which calculates five 3D models. The model with the highest score was chosen for simulations. The D389V mutation was inserted using the mutator plugin of PyMOL 1.8.6.2 (Schrödinger Inc., New York, NY, USA).

\subsection{CORE-MD II Simulation}

The CORE-MD II technique is an enhanced MD-simulation method that relies in part on the partitioning of the entire pathway into short trajectories that we refer to as instances. The CORE-MD II sampling within each instance is accelerated by adaptive path-dependent metadynamics simulations. The second part of the enhanced sampling MD approach involves kinetic Monte Carlo (kMC) sampling between the different configurations that are accessed during each instance. The combination of the partition of the total simulation into short nonequilibrium simulations and the kMC sampling facilitates the sampling of rare events of protein dynamics on long timescales without definitions of a priori reaction pathways and additional parameters.

For the derivation of the CORE-MD II method, a global probability $P\left(x_{i}(t)\right)$ is defined that can be subdivided over $N$ time-slices or subtrajectories $k$ with length $\tau_{k}$, which are described by local probability densities $\rho_{k}\left(x_{i}(t)\right)$ :

$$
\left(x_{i}(t)\right)=\lim _{N \rightarrow \infty} \prod_{k}^{N} \rho_{k}\left(x_{i}(t)\right)
$$

where $x_{i}(t)$ stands for the coordinate of an atom with the index $i$.

In the CORE-MD II formalism, we then consider the averaging process of a trajectorydependent quantity $X(t)$; the partition into small trajectories allows for a faster formation of time averages than the determination of the expectation value of the complete trajectory, which is linked to the timescale problem of MD simulations. Therefore, the expectation value of the complete trajectory can be approximated as:

$$
\langle X(t)\rangle=X(t) P\left(x_{i}(t)\right) \approx X(t) \prod_{k}^{K} \rho_{k}\left(x_{i}(t)\right)
$$

which states that the partition of the complete trajectory into a finite number of $\mathrm{K}$ subtrajectories is approximately sufficient for the sampling of the expectation value $\langle X(t)\rangle$. We define the number of configurations $\mathrm{K}$ by a minimal set of the number of atoms $N_{a}$ in the system, which guarantees a fast forward propagation.

Within each instance $k$, the local pathway is described by the reduced action $L_{i_{k}}(t)$ :

$$
L_{i_{k}}(t)=\sum_{t<\tau_{k}} p_{i}(t) \Delta x_{i}(t)
$$

where $\Delta x_{i}(t)=x_{i}(t)-\left\langle x_{i}(t)\right\rangle, p_{i}(t)$ is the momentum, and $\mathrm{t}$ stands for the time. The local path $L_{i_{k}}(t)$ is used to define the local autocorrelation function $C_{i_{k}}(t)$ :

$$
C_{i_{k}}(t)=\frac{1}{\tau_{k}} \sum_{t \leq \tau_{k}} \frac{\left(L_{i_{k}}(t)-\left\langle L_{i_{k}}(t)\right\rangle\right)\left(L_{i_{k}}\left(t^{\prime}\right)-\left\langle L_{i_{k}}(t)\right\rangle\right)}{\left|L_{i_{k}}(t)-\left\langle L_{i_{k}}(t)\right\rangle\right|\left|L_{i_{k}}\left(t^{\prime}\right)-\left\langle L_{i_{k}}(t)\right\rangle\right|}
$$

where $L_{i_{k}}\left(t^{\prime}\right)$ is determined with a frequency equal to $1 \mathrm{ps}^{-1}$ and $\langle\ldots\rangle$ denotes the time average.

The CORE-MD II [51] technique samples the system along a correlation-dependent probability between states with an index $k$ using a kinetic Monte Carlo $(\mathrm{kMC})$ algorithm. We limit the number of kMC configurations by a minimal set of the number of atoms $N_{a}$ in the system, which guarantees a fast forward propagation within a small window of three possible selections in each kMC step. 
With a frequency of $\tau_{k}$, we perform a kMC step and express a rate $r_{k}$ for each instance $k$. We then calculate the cumulative rates and apply the kinetic Monte Carlo algorithm for the selection of a configuration $\mathrm{k}$ with which a configuration is used for the subsequent trajectory instance. The $\mathrm{kMC}$ sampling guides the trajectory between equilibrium configurations of the system, where each instance $\mathrm{k}$ resembles a state that resides close to the equilibrium state.

We continue with the description of the second component of the CORE-MD II algorithm that applies the local biases. (1) At each initialization of a new trajectory fragment, the velocities are selected from a random distribution. (2) In order to accelerate the sampling within each instance, we apply a history-dependent bias potential that is related to metadynamics [88], while the history dependency is limited by the timescale of each instance. We add the Gaussians to the history-dependent potential using the well-tempered metadynamics technique through a normalization of the added Gaussians by the factor. The corresponding bias is added throughout the simulation.

Finally, we accelerate the sampling within each instance and apply the statistical bias as described in our recent work on the CORE-MD algorithm. We implemented the correlation-dependent bias by a factorization with the variable $\lambda_{i_{k}}(t)$ with which we scale the gradient of all atoms in the system. This statistical bias enhances the decay of the correlation function and accelerates the access of new states by the system.

For the enhanced MD simulations and the trajectory analysis, we used a modified version of the GROMACS 4.5.5 simulation package [49-51]. For the setup of our simulations, we centered the homology model of the NMR structure (PDB: 5k6p) in a cubic box with dimensions $5.75 \times 5.75 \times 5.75 \mathrm{~nm}^{3}$. For the description of the interactions in the system, we used the AMBER99SB force field $[89,90]$. The simulations have been performed in implicit solvent (GBSA), while the electrostatic and van der Waals (vdW) interactions were calculated using a twin-range cutoff of $1.2 / 1.0 \mathrm{~nm}$. The neighbor list with a neighbor list cutoff equal to $1.0 \mathrm{~nm}$ was updated every second integration step. The simulations were carried out in the constant-NVT ensemble at a target temperature equal to $300 \mathrm{~K}$. For temperature control, we used the Nosé-Hoover thermostat with a coupling constant $\tau_{\mathrm{T}}$ equal to $1.0 \mathrm{ps}$.

\subsection{Trajectory Analysis}

In order to define the free energy landscapes, we projected the free energy on the interatomic distances that we identified as principal coordinates (distance definitions). We defined the free energies $\Delta F$ using the relation [91]:

$$
\Delta F=k_{b} T \frac{P_{i}}{P_{\min }}
$$

To compare the free energy landscapes of two conformational distributions, we calculated the free energy differences $\Delta \Delta F$ :

$$
\Delta \Delta F=\Delta F_{1}-\Delta F_{2}
$$

Using the same distance definition, we performed a clustering of states with a cutoff of $0.2 \mathrm{~nm}$, in order to determine whether a conformation belongs to a state. We calculated the transition probabilities and the probability for the occurrence of a state using the relative counts of each cluster in relation to the total number of conformations within each state.

\subsection{Plasmid Construction}

C0-C2 and C2 constructs of MyBPC (UniProt Q14896) with a C-terminal 6xHis-tag were generated from the human full-length cDNA. Gene fragments derived from conventional PCR were inserted between the NdeI and EcoRI sites of pET23a(+). C0-C2 comprises the residues 1-452 and C2 the residues 362-452, consistent with the UniProt entry. D389V variants were generated using site-directed whole plasmid mutagenesis. 


\subsection{Protein Purification}

Human MyBPC (Uniprot Q14896) constructs C2 and C0-C2 were produced in Escherichia coli Rosetta(DE3)pLysS cells. Purification was performed as described in previous studies [15,16]. MyBPC C2 and C0-C2 were affinity-purified using PureCube $100 \mathrm{Ni}-$ NTA Agarose (Cube Biotech, Monheim am Rhein, Germany). Protein purity was assessed using SDS-PAGE [92], and protein concentration was determined photometrically using calculated extinction coefficients at $280 \mathrm{~nm}$ of $10,095 \mathrm{~L} \mathrm{~mol}^{-1} \mathrm{~cm}^{-1}$ for $\mathrm{C} 2$ and $42,650 \mathrm{~L} \mathrm{~mol}^{-1} \mathrm{~cm}^{-1}$ for C0-C2 [93,94]. C2 was subsequently applied to a Superdex 16/600 S75 size exclusion chromatography column (GE Healthcare, Chicago, IL, USA). C0-C2 was further purified using a HiTrap SP HP $5 \mathrm{~mL}$ cation exchange column (Cytiva Life Sciences, Marlborough, MA, USA). Trehalose was supplemented to $10 \%(w / v)$; protein aliquots were flash-frozen in liquid $\mathrm{N}_{2}$ and stored at $-80{ }^{\circ} \mathrm{C}$ until usage.

$\beta$-CM from Sus scrofa left ventricular tissue (Uniprot P79293, Q5EFJ2, Q8MHY0) was purified as described in [95]. $\alpha$-Cardiac actin (Uniprot B6VNT8) was extracted from acetone powder of Sus scrofa cardiac tissue according to [96].

\subsection{Thermal Stability of MyBPC Subdomains}

Protein thermostability was explored in a thermal shift assay (TSA) [97] using SYPRO Orange Protein Gel Stain (Thermo Fisher Scientific, Waltham, MA, USA). C2 was diluted to a concentration of $0.2 \mathrm{mg} / \mathrm{mL}$ in a buffer containing $10 \mathrm{mM}$ HEPES pH 7.4, $100 \mathrm{mM}$ $\mathrm{NaCl}, 1 \mathrm{mM}$ EDTA, and $1 \mathrm{mM}$ DTT. C0-C2 was adjusted to $0.5 \mathrm{mg} / \mathrm{mL}$ in the same buffer containing $150 \mathrm{mM} \mathrm{NaCl}$. Protein solution was subjected to a temperature gradient of 25 to $80^{\circ} \mathrm{C}$ and fluorescence was monitored using a StepOne Real-Time PCR System (Applied Biosystems, Waltham, MA, USA). Protein melting temperature $\left(T_{m}\right)$ was determined as the midpoint of fluorescence increase.

Differential scanning calorimetry (DSC) was performed using a Nano DSC Model 6300 Differential Scanning Calorimeter (TA Instruments, New Castle, DE, USA). C0-C2 was diluted to $1.5 \mathrm{mg} / \mathrm{mL}$ and $\mathrm{C} 2$ to $3.0 \mathrm{mg} / \mathrm{mL}$ in the buffers mentioned above. The protein solutions were subjected to a temperature gradient of 25 to $70^{\circ} \mathrm{C}$ and the amount of heat required to increase temperature was monitored. The maximum of the acquired curve corresponded to $\mathrm{T}_{\mathrm{m}}$. Data were analyzed using NanoAnalyze software (TA Instruments, New Castle, DE, USA).

\subsection{Circular Dichroism Measurements}

Circular dichroism measurements were performed using PiStar 180 CD spectrometer (Applied Photophysics, Leatherhead, UK). Proteins were diluted into $10 \mathrm{mM} \mathrm{NaP}_{\mathrm{i}}$ buffer $\mathrm{pH} 7.4$ with $0.2 \mathrm{mg} / \mathrm{mL}$ MyBPC C0-C2 and $0.1 \mathrm{mg} / \mathrm{mL}$ MyBPC final concentrations. Circular dichroism was recorded as millidegrees for wavelengths from 260 to $176 \mathrm{~nm}$ with a bandwidth of $4 \mathrm{~nm}$ for buffer and protein solutions. Data for each wavelength were obtained for $10 \mathrm{~s}$ and each protein was measured as a triplicate. Data were averaged and buffer subtracted before smoothening using the Savitzky-Golay filter with a polynomial power of 2. Preprocessed data were analyzed using the DichroWeb server [98] and a set of reference spectra for wavelengths from 185 to $240 \mathrm{~nm}$ [99]. The output of the analysis was the mean residue ellipticity for each wavelength and the resulting calculated relative amounts of $\alpha$-helical, $\beta$-sheet, and unordered regions.

\subsection{High-Speed Cosedimentation Assay}

High-speed cosedimentation assays were used to study protein-protein interactions as described previously $[100,101]$. G-actin was polymerized for $3 \mathrm{~h}$ at room temperature by the addition of $\mathrm{MgCl}_{2}$ to $2 \mathrm{mM}$ and $\mathrm{KCl}$ to $100 \mathrm{mM}$. F-actin $(0-40 \mu \mathrm{M})$ was incubated with $5 \mu \mathrm{M} \mathrm{C} 0-\mathrm{C} 2$ or $30 \mu \mathrm{M}$ C2 in $25 \mathrm{mM}$ HEPES $\mathrm{pH} 7.3,25 \mathrm{mM} \mathrm{KCl}, 5 \mathrm{mM} \mathrm{MgCl}_{2}$, and $1 \mathrm{mM}$ EGTA for $30 \mathrm{~min}$ at room temperature. Reaction setups were centrifuged for $30 \mathrm{~min}$ at 55,000 rpm using a TLA-55 rotor in an Optima TLX Ultracentrifuge (Beckman Coulter, Brea, CA, USA). Protein content in supernatant and pellet samples was analyzed using SDS- 
PAGE and densitometric quantification with Image Lab (Bio-Rad Laboratories, Hercules, CA, USA).

Synthetic thick filaments of full-length $\beta$-CM were created by adjusting buffer conditions to $20 \mathrm{mM}$ HEPES pH 7.4, $75 \mathrm{mM} \mathrm{NaCl}, 2 \mathrm{mM} \mathrm{MgCl}_{2}, 0.5 \mathrm{mM}$ EDTA, and $0.5 \mathrm{mM}$ DTT and incubation on ice for $30 \mathrm{~min}$ prior to the experiment. $\beta-\mathrm{CM}(2.5 \mu \mathrm{M})$ was incubated with $0-30 \mu \mathrm{M} \mathrm{C} 0-\mathrm{C} 2$ or $\mathrm{C} 2$ for $30 \mathrm{~min}$ at room temperature. Centrifugation was performed as above and pellet fractions were analyzed using SDS-PAGE. Amount of protein in the pellet fractions was determined via a protein standard range.

Data analysis was performed using Origin 2020b (OriginLab, Northampton, MA, USA).

\subsection{Steered Molecular Dynamics Simulation}

The mechanostability of $\mathrm{C} 2$ was assessed using constant velocity steered molecular dynamics (cvSMD) simulations [66-68] employing NAMD 2.14 [102] with CHARMM36 force fields [103]. The C2 domain was modeled as described above. Temperature was set to $310 \mathrm{~K}$ and the GBIS model was used with an alpha-cutoff of $1.2 \mathrm{~nm}$ and an ion concentration of $150 \mathrm{mM} \mathrm{NaCl}$. Scaled1-4 was used for nonbonded interactions with a cutoff of $1.4 \mathrm{~nm}$ and a switching function at $1.0 \mathrm{~nm}$. A Langevin Nosé-Hoover thermostat was applied with a damping constant of $5.0 / \mathrm{ps}$ and hydrogen coupling enabled. Atom restraints were applied to both the fixed and the SMD atom with an exponent for position restraint energy function of 2 and a constraint scaling factor of 1.0. Molecules were equilibrated for $1 \mathrm{~ns}$ before performing a $20 \mathrm{~ns}$ unfolding simulation. The SMD atom was moved at a constant velocity of $0.01 \AA / \mathrm{ps}$ with a force constant of $7 \mathrm{kcal} / \mathrm{mol} / \AA$ equaling $486.4 \mathrm{pN} \AA$ over the course of $20 \mathrm{~ns}$ along the vector defined by the way from the fixed to the SMD atom. Results were analyzed by multiplying the force in $x, y$, and $z$ directions acting on the SMD atom with the normalized direction of pulling and plotting the result against the time. Data were smoothened using Savitzky-Golay filter to compensate for the noise created by the spring acting on the fixed atom. Averaged force-time curves consist of 10 separate unfolding simulations per construct.

Supplementary Materials: The following are available online at https://www.mdpi.com/article/10.3 390/ijms222111949/s1.

Author Contributions: Conceptualization: F.V.S. and D.J.M.; methodology: F.V.S. purified protein and performed biochemical experiments, F.V.S. and E.K.P. conducted MD simulations and performed the analysis; software: E.K.P. developed the CORE-MD II method used in this study; writingoriginal draft preparation: F.V.S.; writing—review and editing: F.V.S., M.H.T., E.K.P. and D.J.M.; visualization: F.V.S. and E.K.P.; supervision: M.H.T. and D.J.M.; project administration, funding acquisition: D.J.M. All authors have read and agreed to the published version of the manuscript.

Funding: D.J.M. was supported by Deutsche Forschungsgemeinschaft (DFG) grant MA1081/23-1. D.J.M. is a member of the European Joint Project on Rare Diseases Consortium "PredACTINg" with support from the German Federal Ministry of Education and Research under Grant Agreement 01GM1922B and a member of the Cluster of Excellence RESIST (EXC 2155) DFG Project ID 39087428B11. M.H.T. received support from the Volkswagen Foundation, Joint Lower Saxony-Israeli Research Projects, grant number VWZN3012.

Institutional Review Board Statement: Not applicable.

Informed Consent Statement: Not applicable.

Data Availability Statement: Not applicable.

Acknowledgments: We thank Claudia Thiel for excellent technical assistance. F.V.S. was enrolled in the $\mathrm{PhD}$ program Molecular Medicine of Hannover Biomedical Research School (HBRS).

Conflicts of Interest: The authors declare no conflict of interest. 


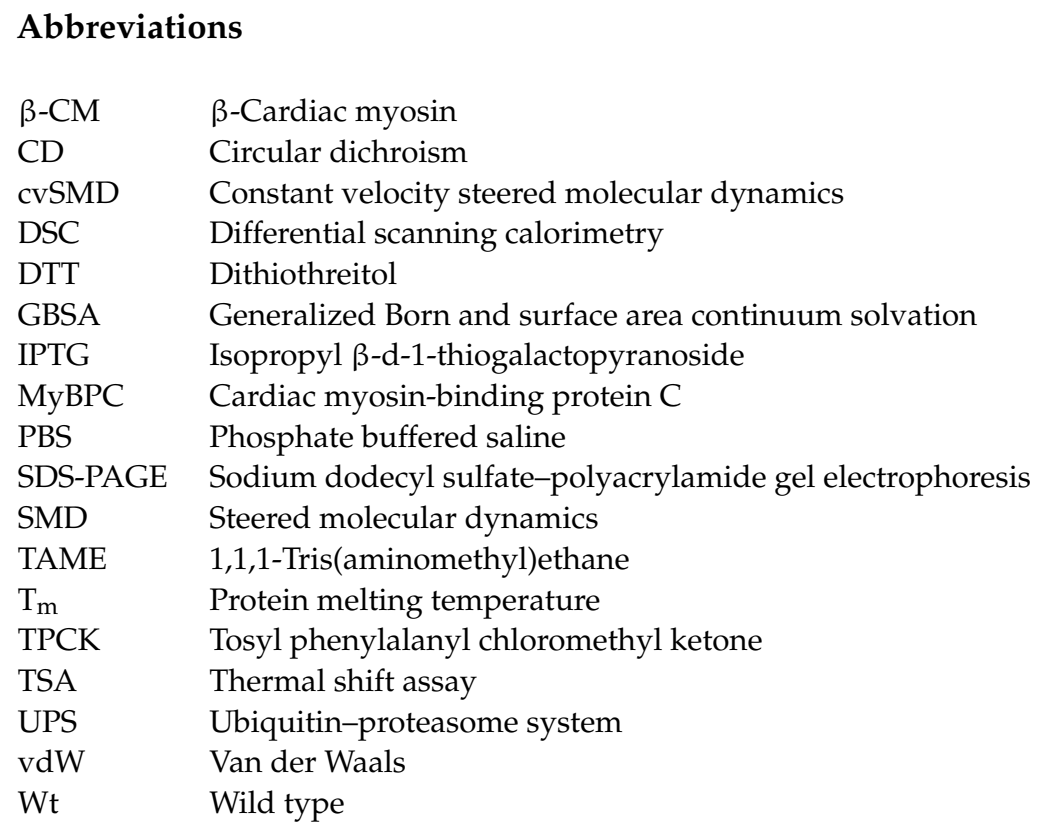

\section{References}

1. Semsarian, C.; Ingles, J.; Maron, M.S.; Maron, B.J. New perspectives on the prevalence of hypertrophic cardiomyopathy. J. Am. Coll. Cardiol. 2015, 65, 1249-1254. [CrossRef] [PubMed]

2. Maron, B.J.; Maron, M.S. Hypertrophic cardiomyopathy. Lancet 2013, 381, 242-255. [CrossRef]

3. Barsheshet, A.; Brenyo, A.; Moss, A.J.; Goldenberg, I. Genetics of sudden cardiac death. Curr. Cardiol. Rep. 2011, 13, 364-376. [CrossRef] [PubMed]

4. Wang, L.; Seidman, J.G.; Seidman, C.E. Narrative review: Harnessing molecular genetics for the diagnosis and management of hypertrophic cardiomyopathy. Ann. Intern. Med. 2010, 152, 513-520. [CrossRef]

5. Maron, B.J.; Sato, N.; Roberts, W.C.; Edwards, J.E.; Chandra, R.S. Quantitative analysis of cardiac muscle cell disorganization in the ventricular septum. Comparison of fetuses and infants with and without congenital heart disease and patients with hypertrophic cardiomyopathy. Circulation 1979, 60, 685-696. [CrossRef] [PubMed]

6. Carrier, L.; Mearini, G.; Stathopoulou, K.; Cuello, F. Cardiac myosin-binding protein C (MYBPC3) in cardiac pathophysiology. Gene 2015, 573, 188-197. [CrossRef]

7. Heling, L.W.H.J.; Geeves, M.A.; Kad, N.M. MyBP-C: One protein to govern them all. J. Muscle Res. Cell Motil. 2020, 41, 1-11. [CrossRef] [PubMed]

8. Barefield, D.; Sadayappan, S. Phosphorylation and function of cardiac myosin binding protein-C in health and disease. J. Mol. Cell. Cardiol. 2010, 48, 866-875. [CrossRef]

9. Kuster, D.W.D.; Bawazeer, A.C.; Zaremba, R.; Goebel, M.; Boontje, N.M.; van der Velden, J. Cardiac myosin binding protein C phosphorylation in cardiac disease. J. Muscle Res. Cell Motil. 2012, 33, 43-52. [CrossRef]

10. Freiburg, A.; Gautel, M. A molecular map of the interactions between titin and myosin-binding protein C. Eur. J. Biochem. 1996, 235, 317-323. [CrossRef]

11. Furst, D.O.; Vinkemeier, U.; Weber, K. Mammalian skeletal muscle c-protein: Purification from bovine muscle, binding to titin and the characterization of a full-length human CDNA. J. Cell Sci. 1992, 102, 769-778. [CrossRef]

12. Offer, G.; Moos, C.; Starr, R. A new protein of the thick filaments of vertebrate skeletal myofibrils: Extraction, purification and characterization. J. Mol. Biol. 1973, 74, 653-676. [CrossRef]

13. Flashman, E.; Redwood, C.; Moolman-Smook, J.; Watkins, H. Cardiac myosin binding protein C. Circ. Res. 2004, 94, 1279-1289. [CrossRef]

14. Moos, C.; Mason, C.M.; Besterman, J.M.; Feng, I.-N.M.; Dubin, J.H. The binding of skeletal muscle C-protein to F-actin, and its relation to the interaction of actin with myosin subfragment-1. J. Mol. Biol. 1978, 124, 571-586. [CrossRef]

15. Razumova, M.V.; Shaffer, J.F.; Tu, A.-Y.; Flint, G.V.; Regnier, M.; Harris, S.P. Effects of the N-terminal domains of myosin binding protein-C in an in vitro motility assay: Evidence for long-lived cross-bridges. J. Biol. Chem. 2006, 281, 35846-35854. [CrossRef]

16. Shaffer, J.F.; Kensler, R.W.; Harris, S.P. The myosin-binding protein C motif binds to F-actin in a phosphorylation-sensitive manner. J. Biol. Chem. 2009, 284, 12318-12327. [CrossRef] [PubMed]

17. Whitten, A.E.; Jeffries, C.M.; Harris, S.P.; Trewhella, J. Cardiac myosin-binding protein C decorates F-actin: Implications for cardiac function. Proc. Natl. Acad. Sci. USA 2008, 105, 18360-18365. [CrossRef] [PubMed]

18. Gruen, M.; Gautel, M. Mutations in $\beta$-Myosin S2 That cause familial hypertrophic cardiomyopathy (FHC) abolish the interaction with the regulatory domain of myosin-binding protein-C. J. Mol. Biol. 1999, 286, 933-949. [CrossRef] 
19. Gruen, M.; Prinz, H.; Gautel, M. CAPK-Phosphorylation Controls the Interaction of the Regulatory Domain of Cardiac Myosin Binding Protein C with Myosin-S2 in an on-off Fashion. FEBS Lett. 1999, 453, 254-259. [CrossRef]

20. Starr, R.; Offer, G. The interaction of C-protein with heavy meromyosin and subfragment-2. Biochem. J. 1978, 171, 813-816. [CrossRef]

21. McNamara, J.W.; Li, A.; Smith, N.J.; Lal, S.; Graham, R.M.; Kooiker, K.B.; van Dijk, S.J.; Remedios, C.G.D.; Harris, S.P.; Cooke, R. Ablation of cardiac myosin binding protein-C disrupts the super-relaxed state of myosin in murine cardiomyocytes. J. Mol. Cell. Cardiol. 2016, 94, 65-71. [CrossRef]

22. McNamara, J.W.; Singh, R.R.; Sadayappan, S. Cardiac myosin binding protein-C phosphorylation regulates the super-relaxed state of myosin. Proc. Natl. Acad. Sci. USA 2019, 116, 11731-11736. [CrossRef]

23. Toepfer, C.N.; Wakimoto, H.; Garfinkel, A.C.; McDonough, B.; Liao, D.; Jiang, J.; Tai, A.C.; Gorham, J.M.; Lunde, I.G.; Lun, M.; et al. Hypertrophic cardiomyopathy mutations in MYBPC3 dysregulate myosin. Sci. Transl. Med. 2019, 11. [CrossRef]

24. Kampourakis, T.; Ponnam, S.; Sun, Y.-B.; Sevrieva, I.; Irving, M.M. Structural and functional effects of myosin-binding protein-C phosphorylation in heart muscle are not mimicked by serine-to-aspartate substitutions. J. Biol. Chem. 2018, 293, 14270-14275. [CrossRef]

25. Inchingolo, A.V.; Previs, S.B.; Previs, M.J.; Warshaw, D.M.; Kad, N.M. Revealing the mechanism of how cardiac myosin-binding protein C N-terminal fragments sensitize thin filaments for myosin binding. Proc. Natl. Acad. Sci. USA 2019, 116, $6828-6835$. [CrossRef]

26. Karsai, Á.; Kellermayer, M.S.Z.; Harris, S.P. Mechanical unfolding of cardiac myosin binding protein-C by atomic force microscopy. Biophys. J. 2011, 101, 1968-1977. [CrossRef] [PubMed]

27. Karsai, Á.; Kellermayer, M.S.Z.; Harris, S.P. Cross-species mechanical fingerprinting of cardiac myosin binding protein-C. Biophys. J. 2013, 104, 2465-2475. [CrossRef]

28. Weith, A.; Sadayappan, S.; Gulick, J.; Previs, M.J.; VanBuren, P.; Robbins, J.; Warshaw, D.M. Unique single molecule binding of cardiac myosin binding protein-C to actin and phosphorylation-dependent inhibition of actomyosin motility requires 17 amino acids of the motif domain. J. Mol. Cell. Cardiol. 2012, 52, 219-227. [CrossRef]

29. Notredame, C.; Higgins, D.G.; Heringa, J. T-Coffee: A novel method for fast and accurate multiple sequence alignment. J. Mol. Biol. 2000, 302, 205-217. [CrossRef] [PubMed]

30. Waterhouse, A.M.; Procter, J.B.; Martin, D.M.A.; Clamp, M.; Barton, G.J. Jalview version 2-A multiple sequence alignment editor and analysis workbench. Bioinformatics 2009, 25, 1189-1191. [CrossRef] [PubMed]

31. Ababou, A.; Gautel, M.; Pfuhl, M. Dissecting the N-terminal myosin binding site of human cardiac myosin-binding protein C. structure and myosin binding of domain C2. J. Biol. Chem. 2007, 282, 9204-9215. [CrossRef]

32. Helms, A.S.; Thompson, A.D.; Glazier, A.A.; Hafeez, N.; Kabani, S.; Rodriguez, J.; Yob, J.M.; Woolcock, H.; Mazzarotto, F.; Lakdawala, N.K.; et al. Spatial and functional distribution of MYBPC3 pathogenic variants and clinical outcomes in patients with hypertrophic cardiomyopathy. Circ. Genom. Precis. Med. 2020, 13, 396-405. [CrossRef]

33. Marston, S.; Copeland, O.; Jacques, A.; Livesey, K.; Tsang, V.; McKenna, W.J.; Jalilzadeh, S.; Carballo, S.; Redwood, C.; Watkins, H. Evidence from human myectomy samples that MYBPC3 mutations cause hypertrophic cardiomyopathy through haploinsufficiency. Circ. Res. 2009, 105, 219-222. [CrossRef] [PubMed]

34. O'Leary, T.S.; Snyder, J.; Sadayappan, S.; Day, S.M.; Previs, M.J. MYBPC3 Truncation mutations enhance actomyosin contractile mechanics in human hypertrophic cardiomyopathy. J. Mol. Cell. Cardiol. 2019, 127, 165-173. [CrossRef] [PubMed]

35. van Dijk, S.J.; Dooijes, D.; dos Remedios, C.; Michels, M.; Lamers, J.M.J.; Winegrad, S.; Schlossarek, S.; Carrier, L.; ten Cate, F.J.; Stienen, G.J.M.; et al. Cardiac myosin-binding protein C mutations and hypertrophic cardiomyopathy. Circulation 2009, 119, 1473-1483. [CrossRef]

36. Barefield, D.; Kumar, M.; Gorham, J.; Seidman, J.G.; Seidman, C.E.; de Tombe, P.P.; Sadayappan, S. Haploinsufficiency of MYBPC3 exacerbates the development of hypertrophic cardiomyopathy in heterozygous mice. J. Mol. Cell. Cardiol. 2015, 79, 234-243. [CrossRef]

37. Glazier, A.A.; Thompson, A.; Day, S.M. Allelic imbalance and haploinsufficiency in MYBPC3-Linked hypertrophic cardiomyopathy. Pflugers Arch.-Eur. J. Physiol. 2019, 471, 781-793. [CrossRef]

38. Helms, A.S.; Davis, F.M.; Coleman, D.; Bartolone, S.N.; Glazier, A.A.; Pagani, F.; Yob, J.M.; Sadayappan, S.; Pedersen, E.; Lyons, R.; et al. Sarcomere mutation-specific expression patterns in human hypertrophic cardiomyopathy. Circ. Cardiovasc. Genet. 2014, 7 , 434-443. [CrossRef]

39. Nadvi, N.A.; Michie, K.A.; Kwan, A.H.; Guss, J.M.; Trewhella, J. Clinically linked mutations in the central domains of cardiac myosin-binding protein C with distinct phenotypes show differential structural effects. Structure 2016, 24, 105-115. [CrossRef] [PubMed]

40. Bezold, K.L.; Shaffer, J.F.; Khosa, J.K.; Hoye, E.R.; Harris, S.P. A gain-of-function mutation in the m-domain of cardiac myosinbinding protein-C increases binding to actin. J. Biol. Chem. 2013, 288, 21496-21505. [CrossRef]

41. van Dijk, S.J.; Bezold Kooiker, K.; Mazzalupo, S.; Yang, Y.; Kostyukova, A.S.; Mustacich, D.J.; Hoye, E.R.; Stern, J.A.; Kittleson, M.D.; Harris, S.P. The A31P missense mutation in cardiac myosin binding protein $C$ alters protein structure but does not cause haploinsufficiency. Arch. Biochem. Biophys. 2016, 601, 133-140. [CrossRef]

42. Smelter, D.F.; Lange, W.J.D.; Cai, W.; Ge, Y.; Ralphe, J.C. The HCM-Linked W792R mutation in cardiac myosin binding protein-C reduces C6 FnIII domain stability. Am. J. Physiol.-Heart Circ. Physiol. 2018, 314, H1179-H1191. [CrossRef] [PubMed] 
43. Sakthievel, S.; Waldmüller, S.; Saadi, A.; Joseph, P.K.; Rakesh, P.G.; Padmakumar, R.; Jagan, M.T.; Richard, P.; Schwartz, K.; Rajamanickam, C.; et al. Novel mutations in MYH7 and MYBPC3 of an Indian family causing hypertrophic cardiomyopathy. J. Mol. Cell. Cardiol. 2001, 33, A105. [CrossRef]

44. Waldmüller, S.; Sakthivel, S.; Saadi, A.V.; Selignow, C.; Rakesh, P.G.; Golubenko, M.; Joseph, P.K.; Padmakumar, R.; Richard, P.; Schwartz, K.; et al. Novel deletions in MYH7 and MYBPC3 identified in Indian families with familial hypertrophic cardiomyopathy. J. Mol. Cell. Cardiol. 2003, 35, 623-636. [CrossRef]

45. Dhandapany, P.S.; Sadayappan, S.; Xue, Y.; Powell, G.T.; Rani, D.S.; Nallari, P.; Rai, T.S.; Khullar, M.; Soares, P.; Bahl, A.; et al. A common MYBPC3 (cardiac myosin binding protein C) variant associated with cardiomyopathies in South Asia. Nat. Genet. 2009, 41, 187-191. [CrossRef]

46. Kuster, D.W.D.; Govindan, S.; Springer, T.I.; Martin, J.L.; Finley, N.L.; Sadayappan, S. A hypertrophic cardiomyopathy-associated MYBPC3 mutation common in populations of South Asian descent causes contractile dysfunction. J. Biol. Chem. 2015, 290, 5855-5867. [CrossRef] [PubMed]

47. Kuster, D.W.D.; Lynch, T.L.; Barefield, D.Y.; Sivaguru, M.; Kuffel, G.; Zilliox, M.J.; Lee, K.H.; Craig, R.; Namakkal-Soorappan, R.; Sadayappan, S. Altered C10 domain in cardiac myosin Binding protein-C results in hypertrophic cardiomyopathy. Cardiovasc. Res. 2019. [CrossRef]

48. Viswanathan, S.K.; Puckelwartz, M.J.; Mehta, A.; Ramachandra, C.J.A.; Jagadeesan, A.; Fritsche-Danielson, R.; Bhat, R.V.; Wong, P.; Kandoi, S.; Schwanekamp, J.A.; et al. Association of cardiomyopathy with MYBPC3 D389V and MYBPC3 $\triangle 25 b p$ intronic deletion in South Asian descendants. JAMA Cardiol. 2018, 3, 481-488. [CrossRef]

49. Hess, B.; Kutzner, C.; Van Der Spoel, D.; Lindahl, E. GROMACS 4: Algorithms for highly efficient, load-balanced, and scalable molecular simulation. J. Chem. Theory Comput. 2008, 4, 435-447. [CrossRef]

50. Pronk, S.; Páll, S.; Schulz, R.; Larsson, P.; Bjelkmar, P.; Apostolov, R.; Shirts, M.R.; Smith, J.C.; Kasson, P.M.; Van Der Spoel, D. GROMACS 4.5: A high-throughput and highly parallel open source molecular simulation toolkit. Bioinformatics 2013, 29, 845-854. [CrossRef]

51. Peter, E.K.; Manstein, D.J.; Shea, J.-E.; Schug, A. CORE-MD II: A fast, adaptive, and accurate enhanced sampling method. J. Chem. Phys. 2021, 155, 104114. [CrossRef] [PubMed]

52. Guarnera, E.; Berezovsky, I.N. Toward comprehensive allosteric control over protein activity. Structure 2019, $27,866-878 . e 1$. [CrossRef] [PubMed]

53. Lu, S.; Shen, Q.; Zhang, J. Allosteric methods and their applications: Facilitating the discovery of allosteric drugs and the investigation of allosteric mechanisms. Acc. Chem. Res. 2019, 52, 492-500. [CrossRef]

54. Pricolo, M.R.; Herrero-Galán, E.; Mazzaccara, C.; Losi, M.A.; Alegre-Cebollada, J.; Frisso, G. Protein thermodynamic destabilization in the assessment of pathogenicity of a variant of uncertain significance in cardiac myosin binding protein C. J. Cardiovasc. Transl. Res. 2020. [CrossRef]

55. Suay-Corredera, C.; Pricolo, M.R.; Velázquez-Carreras, D.; Pathak, D.; Nandwani, N.; Pimenta-Lopes, C.; Sánchez-Ortiz, D.; Urrutia-Irazabal, I.; Vilches, S.; Dominguez, F.; et al. Nanomechanical phenotypes in cardiac myosin-binding protein C mutants that cause hypertrophic cardiomyopathy. ACS Nano 2021, 15, 10203-10216. [CrossRef]

56. Ratti, J.; Rostkova, E.; Gautel, M.; Pfuhl, M. Structure and interactions of myosin-binding protein C domain C0: Cardiac-specific regulation of myosin at its neck? J. Biol. Chem. 2011, 286, 12650-12658. [CrossRef]

57. Kunst, G.; Kress, K.R.; Gruen, M.; Uttenweiler, D.; Gautel, M.; Fink, R.H.A. Myosin binding protein C, a phosphorylationdependent force regulator in muscle that controls the attachment of myosin heads by its interaction with myosin S2. Circ. Res. 2000, 86, 51-58. [CrossRef]

58. Chow, M.L.; Shaffer, J.F.; Harris, S.P.; Dawson, J.F. Altered interactions between cardiac myosin binding protein-c and $\alpha$-cardiac actin variants associated with cardiomyopathies. Arch. Biochem. Biophys. 2014, 550-551, 28-32. [CrossRef]

59. Singh, R.R.; McNamara, J.W.; Sadayappan, S. Mutations in myosin S2 alter cardiac myosin-binding protein-C interaction in hypertrophic cardiomyopathy in a phosphorylation-dependent manner. J. Biol. Chem. 2021, 297, 100836. [CrossRef] [PubMed]

60. Calaghan, S.C.; Trinick, J.; Knight, P.J.; White, E. A Role for C-protein in the regulation of contraction and intracellular Ca2+ in intact rat ventricular myocytes. J. Physiol. 2000, 528, 151-156. [CrossRef]

61. Colson, B.A.; Bekyarova, T.; Locher, M.R.; Fitzsimons, D.P.; Irving, T.C.; Moss, R.L. Protein kinase A-Mediated phosphorylation of CMyBP-C increases proximity of myosin heads to actin in resting myocardium. Circ. Res. 2008, 103, 244-251. [CrossRef] [PubMed]

62. Kensler, R.W.; Craig, R.; Moss, R.L. Phosphorylation of cardiac myosin binding protein C releases myosin heads from the surface of cardiac thick filaments. Proc. Natl. Acad. Sci. USA 2017, 114, E1355-E1364. [CrossRef]

63. Luther, P.K.; Winkler, H.; Taylor, K.; Zoghbi, M.E.; Craig, R.; Padrón, R.; Squire, J.M.; Liu, J. Direct visualization of myosin-binding protein C bridging myosin and actin filaments in intact muscle. Proc. Natl. Acad. Sci. USA 2011, 108, 11423-11428. [CrossRef] [PubMed]

64. Woody, M.S.; Winkelmann, D.A.; Capitanio, M.; Ostap, E.M.; Goldman, Y.E. Single molecule mechanics resolves the earliest events in force generation by cardiac myosin. Elife 2019, 8, e49266. [CrossRef]

65. Bhuiyan, M.S.; Gulick, J.; Osinska, H.; Gupta, M.; Robbins, J. Determination of the critical residues responsible for cardiac myosin binding protein C's interactions. J. Mol. Cell. Cardiol. 2012, 53, 838-847. [CrossRef] [PubMed] 
66. Isralewitz, B.; Gao, M.; Schulten, K. Steered molecular dynamics and mechanical functions of proteins. Curr. Opin. Struct. Biol. 2001, 11, 224-230. [CrossRef]

67. Izrailev, S.; Stepaniants, S.; Isralewitz, B.; Kosztin, D.; Lu, H.; Molnar, F.; Wriggers, W.; Schulten, K. Steered molecular dynamics. In Proceedings of the Computational Molecular Dynamics: Challenges, Methods, Ideas, Berlin, Germany, 21-24 May 1997; Deuflhard, P., Hermans, J., Leimkuhler, B., Mark, A.E., Reich, S., Skeel, R.D., Eds.; Springer: Berlin/Heidelberg, Germany, 1999; pp. 39-65.

68. Lu, H.; Isralewitz, B.; Krammer, A.; Vogel, V.; Schulten, K. Unfolding of titin immunoglobulin domains by steered molecular dynamics simulation. Biophys. J. 1998, 75, 662-671. [CrossRef]

69. Previs, M.J.; Previs, S.B.; Gulick, J.; Robbins, J.; Warshaw, D.M. Molecular mechanics of cardiac myosin-binding protein C in native thick filaments. Science 2012, 337, 1215-1218. [CrossRef]

70. Brenner, B.; Seebohm, B.; Tripathi, S.; Montag, J.; Kraft, T. Familial hypertrophic cardiomyopathy: Functional variance among individual cardiomyocytes as a trigger of FHC-phenotype development. Front. Physiol. 2014, 5, 392. [CrossRef]

71. Kraft, T.; Montag, J.; Radocaj, A.; Brenner, B. Hypertrophic cardiomyopathy. Circ. Res. 2016, 119, 992-995. [CrossRef]

72. Kraft, T.; Montag, J. Altered force generation and cell-to-cell contractile imbalance in hypertrophic cardiomyopathy. Pflugers Arch.-Eur. J. Physiol. 2019, 471, 719-733. [CrossRef]

73. Sadayappan, S.; Puckelwartz, M.J.; McNally, E.M. South Asian-Specific MYBPC3 $\triangle 25 \mathrm{bp}$ intronic deletion and its role in cardiomyopathies and heart failure. Circ. Genom. Precis. Med. 2020, 13, e002986. [CrossRef] [PubMed]

74. Blencowe, B.J. Alternative splicing: New insights from global analyses. Cell 2006, 126, 37-47. [CrossRef] [PubMed]

75. Melamud, E.; Moult, J. Stochastic noise in splicing machinery. Nucleic Acids Res. 2009, 37, 4873-4886. [CrossRef]

76. Ito, K.; Patel, P.N.; Gorham, J.M.; McDonough, B.; DePalma, S.R.; Adler, E.E.; Lam, L.; MacRae, C.A.; Mohiuddin, S.M.; Fatkin, D.; et al. Identification of pathogenic gene mutations in LMNA and MYBPC3 that alter RNA splicing. Proc. Natl. Acad. Sci. USA 2017, 114, 7689-7694. [CrossRef]

77. Dainis, A.; Tseng, E.; Clark, T.A.; Hon, T.; Wheeler, M.; Ashley, E. Targeted long-read rna sequencing demonstrates transcriptional diversity driven by splice-site variation in MYBPC3. Circ. Genom. Precis. Med. 2019, 12, e002464. [CrossRef]

78. Da'as, S.I.; Fakhro, K.; Thanassoulas, A.; Krishnamoorthy, N.; Saleh, A.; Calver, B.L.; Safieh-Garabedian, B.; Toft, E.; Nounesis, G.; Lai, F.A.; et al. Hypertrophic cardiomyopathy-linked variants of cardiac myosin-binding protein C3 display altered molecular properties and actin interaction. Biochem. J. 2018, 475, 3933-3948. [CrossRef]

79. Doh, C.Y.; Li, J.; Mamidi, R.; Stelzer, J. The HCM-Causing Y235S CMyBPC Mutation accelerates contractile function by altering C1 domain structure. Biochim. Biophys. Acta (BBA)-Mol. Basis Dis. 2019, 1865, 661-677. [CrossRef] [PubMed]

80. Li, R.H.L.; Stern, J.A.; Ho, V.; Tablin, F.; Harris, S.P. Platelet activation and clopidogrel effects on ADP-induced platelet activation in cats with or without the A31P mutation in MYBPC3. J. Vet. Intern. Med. 2016, 30, 1619-1629. [CrossRef]

81. Holly, A.C.; Melzer, D.; Pilling, L.C.; Fellows, A.C.; Tanaka, T.; Ferrucci, L.; Harries, L.W. Changes in splicing factor expression are associated with advancing age in man. Mech. Ageing Dev. 2013, 134, 356-366. [CrossRef]

82. Latorre, E.; Harries, L.W. Splicing regulatory factors, ageing and age-related disease. Ageing Res. Rev. 2017, 36, 165-170. [CrossRef]

83. Li, H.; Wang, Z.; Ma, T.; Wei, G.; Ni, T. Alternative splicing in aging and age-related diseases. Transl. Med. Aging 2017, 1, 32-40. [CrossRef]

84. Roux, J.; Robinson-Rechavi, M. Age-dependent gain of alternative splice forms and biased duplication explain the relation between splicing and duplication. Genome Res. 2011, 21, 357-363. [CrossRef] [PubMed]

85. Wang, K.; Wu, D.; Zhang, H.; Das, A.; Basu, M.; Malin, J.; Cao, K.; Hannenhalli, S. Comprehensive map of age-associated splicing changes across human tissues and their contributions to age-associated diseases. Sci. Rep. 2018, 8, 10929. [CrossRef] [PubMed]

86. Michie, K.A.; Kwan, A.H.; Tung, C.-S.; Guss, J.M.; Trewhella, J. A highly conserved yet flexible linker is part of a polymorphic protein-binding domain in myosin-binding protein C. Structure 2016, 24, 2000-2007. [CrossRef]

87. Šali, A.; Blundell, T.L. Comparative protein modelling by satisfaction of spatial restraints. J. Mol. Biol. 1993, $234,779-815$. [CrossRef]

88. Laio, A.; Parrinello, M. Escaping free-energy minima. Proc. Natl. Acad. Sci. USA 2002, 99, 12562-12566. [CrossRef]

89. Hornak, V.; Abel, R.; Okur, A.; Strockbine, B.; Roitberg, A.; Simmerling, C. Comparison of multiple amber force fields and development of improved protein backbone parameters. Proteins Struct. Funct. Bioinform. 2006, 65, 712-725. [CrossRef]

90. Kollman, P.A. Advances and continuing challenges in achieving realistic and predictive simulations of the properties of organic and biological molecules. Acc. Chem. Res. 1996, 29, 461-469. [CrossRef]

91. Kumar, S.; Rosenberg, J.M.; Bouzida, D.; Swendsen, R.H.; Kollman, P.A. THE weighted histogram analysis method for free-energy calculations on biomolecules. I. the method. J. Comput. Chem. 1992, 13, 1011-1021. [CrossRef]

92. Laemmli, U.K. Cleavage of structural proteins during the assembly of the head of bacteriophage T4. Nature 1970, 227, 680-685. [CrossRef]

93. Gasteiger, E.; Gattiker, A.; Hoogland, C.; Ivanyi, I.; Appel, R.D.; Bairoch, A. ExPASy: The proteomics server for in-depth protein knowledge and analysis. Nucleic Acids Res. 2003, 31, 3784-3788. [CrossRef]

94. Gasteiger, E.; Hoogland, C.; Gattiker, A.; Duvaud, S.; Wilkins, M.R.; Appel, R.D.; Bairoch, A. Protein identification and analysis tools on the ExPASy Server. In The Proteomics Protocols Handbook; Human Press: Totowa, NJ, USA, 2005; pp. 571-607. [CrossRef]

95. Margossian, S.S.; Lowey, S. [7] Preparation of myosin and its subfragments from rabbit skeletal muscle. Methods Enzymol. 1982, 85, 55-71. [CrossRef] [PubMed] 
96. Lehrer, S.S.; Kerwar, G. Intrinsic fluorescence of actin. Biochemistry 1972, 11, 1211-1217. [CrossRef] [PubMed]

97. Lo, M.-C.; Aulabaugh, A.; Jin, G.; Cowling, R.; Bard, J.; Malamas, M.; Ellestad, G. Evaluation of Fluorescence-Based Thermal Shift Assays for Hit Identification in Drug Discovery. Anal. Biochem. 2004, 332, 153-159. [CrossRef] [PubMed]

98. Lobley, A.; Whitmore, L.; Wallace, B.A. DICHROWEB: An interactive website for the analysis of protein secondary structure from circular dichroism spectra. Bioinformatics 2002, 18, 211-212. [CrossRef]

99. Sreerama, N.; Woody, R.W. Estimation of protein secondary structure from circular dichroism spectra: Comparison of CONTIN, SELCON, and CDSSTR methods with an expanded reference set. Anal. Biochem. 2000, 287, 252-260. [CrossRef] [PubMed]

100. Taft, M.H.; Behrmann, E.; Munske-Weidemann, L.-C.; Thiel, C.; Raunser, S.; Manstein, D.J. Functional characterization of human myosin-18A and its interaction with F-actin and GOLPH3. J. Biol. Chem. 2013, 288, 30029-30041. [CrossRef]

101. Latham, S.L.; Weiß, N.; Schwanke, K.; Thiel, C.; Croucher, D.R.; Zweigerdt, R.; Manstein, D.J.; Taft, M.H. Myosin-18B regulates higher-order organization of the cardiac sarcomere through thin filament cross-linking and thick filament dynamics. Cell Rep. 2020, 32, 108090. [CrossRef]

102. Phillips, J.C.; Hardy, D.J.; Maia, J.D.C.; Stone, J.E.; Ribeiro, J.V.; Bernardi, R.C.; Buch, R.; Fiorin, G.; Hénin, J.; Jiang, W.; et al. Scalable molecular dynamics on CPU and GPU architectures with NAMD. J. Chem. Phys. 2020, 153, 044130. [CrossRef]

103. Huang, J.; MacKerell, A.D. CHARMM36 All-atom additive protein force field: Validation based on comparison to NMR data. J. Comput. Chem. 2013, 34, 2135-2145. [CrossRef] [PubMed] 